Research papers

\title{
Ex-situ estimation of interception storage capacity of small urban plant species
}

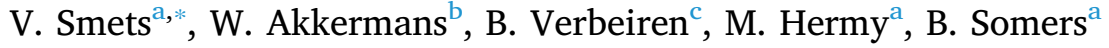 \\ ${ }^{a}$ Division Forest, Nature and Landscape, Department of Earth and Environmental Sciences, KU Leuven, Celestijnenlaan $200 E, 3001$ Heverlee, Belgium \\ ${ }^{\mathrm{b}}$ Division of Mechatronics, Biostatistics and Sensors (MeBioS), KU Leuven, Kasteelpark Arenberg 30, 3001 Heverlee, Belgium \\ ${ }^{\mathrm{c}}$ Department of Hydrology and Hydraulic Engineering, Vrije Universiteit Brussel, Pleinlaan 2, BE-1050 Brussels, Belgium
}

\section{A R T I C L E I N F O}

This manuscript was handled by Marco Borga, Editor-in-Chief, with the assistance of Shengping Wang, Associate Editor Keywords: Interception storage capacity Urban plant species Rainfall simulator experiments Multiple regression analysis Vegetative characteristics Biomass- and storage capacity models

\begin{abstract}
A B S T R A C T
An important knowledge gap in current urban hydrological models are reliable, generic data about interception storage capacities of small urban plant species. These data are crucial to calculate interception losses and learning their effect on the urban hydrological cycle. This study addresses this knowledge gap through simulating rainfall events in an ex-situ, controlled environment on several urban plant species. Four plant species, Lonicera nitida, Lavandula angustifolia, Pennisetum alopecuroides and a grass mix were selected based on their abundance in urban environments and their morphological differences. Several vegetation characteristics such as height and diameter were altered to create as much variation as possible in the dataset to determine the underlying characteristics influencing the interception storage capacity. Estimating the interception storage capacity of each plant $\left(S_{P}\right)$ using multiple linear regression models, biomass $\left(B_{P}\right)$ was found to be the most important predictor variable for all species. Therefore predictive models to estimate the biomass of an individual plant were developed, using some easy to measure vegetation characteristics. When using the results of these biomass models as input in the storage capacity models, reasonable estimations of interception storage capacity were achieved with mean absolute errors between 17.7 and $40.8 \%$, depending on the model. Extrapolating $\mathrm{S}_{\mathrm{P}}$ to a reference area of one $\mathrm{m}^{2}$ showed that L. angustifolia had the highest interception storage capacity due to its high biomass density, followed by P. alopecuroides, L. nitida and finally the grass mix. As a proof of concept, a mixed modelling approach was proposed to include species not covered in this research in the analysis. The findings in this research can be used to create a firm basis for calculations of intra- and interspecies interception storage capacities, essential for improving current urban hydrological models.
\end{abstract}

\section{Introduction}

\subsection{Context}

Regulating ecosystem services provided by urban green are diverse: ranging from carbon and fine particle sequestration to urban heat regulation (Cameron and Blanuša, 2016; Livesley et al., 2016). One of the more prominent services is the ability of vegetation to regulate water flows (e.g. Martin-Ortega et al., 2015). The natural water flow or hydrological cycle of urban areas is altered due to increased imperviousness in the urban environment which results in more frequent flooding and other water related problems such as reduced infiltration and groundwater recharge (Haase, 2009; Jacobson, 2011; Paul and Meyer, 2001). Most cities are built with the idea that incoming rainwater should be guided to the sewer system as quickly as possible after which it will be diverted away from the city. In recent decades however, the idea has been growing that rainwater is a utility rather than an inconvenience and efforts have been made to develop systems that keep rainwater within the city as a temporal storage or to supply the bluegreen network (Demuzere et al., 2014; FAWB, 2009). The idea of using rainwater in our cities to regulate the hydrological balance is known under different names such as 'Water sensitive urban design (WSUD)' (Coutts et al., 2012; Wong et al., 2013), 'Low Impact Development (LID)' (Dietz, 2007) or 'Sustainable Drainage Systems (SuDS)' (Ciria, 2013). Because of its high surface area to volume ratio and relatively low-cost implementation, vegetation has a great potential in acting as a temporal water storage buffer. Additionally the IPCC states that vegetation can make our cities more resilient against negative impacts of climate change such as an increased flood risk and mitigating the urban heat island effect (Revi et al., 2014).

\footnotetext{
* Corresponding author.

E-mail address: vincent.smets@kuleuven.be (V. Smets).
} 
Plants alter the urban hydrological balance by intercepting rainwater. Interception is defined as the process of precipitation falling on vegetation surfaces where it is temporally stored. This water is then either evaporated into the atmosphere, absorbed by leaf surfaces or falls through to the ground surface (Xiao et al., 2000a). The rainwater interception potential of vegetation has been extensively studied and modelled in the past for forest canopies by the Rutter and Gash models (Gash, 1979; Rutter et al., 1971). These models served as foundation on which several authors continued making progress in forest interception modelling (e.g. Muzylo et al., 2009). In more recent decades a shift occurred towards smaller scale crown interception in solitary trees to determine the influence of street trees on the urban water balance (Xiao et al., 2000a; Xiao and McPherson, 2011). The urban vegetation spectrum however does not only consists of trees but also has an abundance of other types of smaller plants such as shrubs and grasses. In terms of water balance studies, these plant types have largely been ignored by the scientific community. Dunkerley (2000), in his review of interception methods, related that to the need to refine measurement techniques for these smaller plant types and he goes even further and implicated that most published estimates of interception loss are probably based on inadequate data and methods. Small plants and their vegetation nevertheless, are an integral part of urban vegetation and, due to their abundance in parks and private gardens, contribute to the water storage potential of urban green (Dewaelheyns et al., 2014; Verbeeck et al., 2013). From a management perspective, they are easier to install and sustain than trees and can be implemented in more diverse locations.

\subsection{Storage capacity: definition and confusion}

The most important plant characteristic influencing the rainwater interception process is the interception storage capacity. There has been some confusion in literature regarding the definition of this term.

The core of this confusion lies in distinguishing the difference between the temporal maximum storage that can be reached during a rainfall event and the 'real' storage capacity. Meteorological variables such as rain intensity and droplet size can influence the amount of water retained on a canopy to an extent that it temporarily exceeds the 'real' storage capacity. This is demonstrated in the experiments of Keim et al. (2006). They found, while simulating rainfall of different intensities to determine interception storage capacities of small vegetation, a drop in actual water storage immediately after stopping the rainfall simulation. This drop, they reasoned, is a result of dripping and evaporation, with the evaporation process becoming more dominant as time increases. The amount of water stored during the rainfall event that is lost immediately after the rain stops hence is not a part of the real storage capacity. Keim et al. (2006) concluded from their experiments that there are two types of storage capacity: first there is the static storage capacity which is the result of an equilibrium of static forces at the contact between water, vegetation and the atmosphere. This storage capacity is largely independent from meteorological variables and evaporation losses from vegetation canopies depend mostly on this storage capacity. It can best be measured after rainfall when canopy drip has ceased.

The temporal maximum storage reached during a rainfall event is defined by Keim et al. (2006) as a second type of storage, the dynamic storage capacity. This storage capacity is the result of dynamic forces generated on the vegetation surfaces through meteorological variables such as rainfall intensity and droplet size. The excess water will be removed mainly through drip during the first few minutes after rain has stopped.

More recently, Xiao and McPherson (2016) tackled this confusion in a similar way: they called the static storage capacity the surface saturation- or minimum storage capacity and the dynamic storage capacity the detention- or maximum storage capacity.

This study focuses on the static storage - (Keim et al., 2006) or

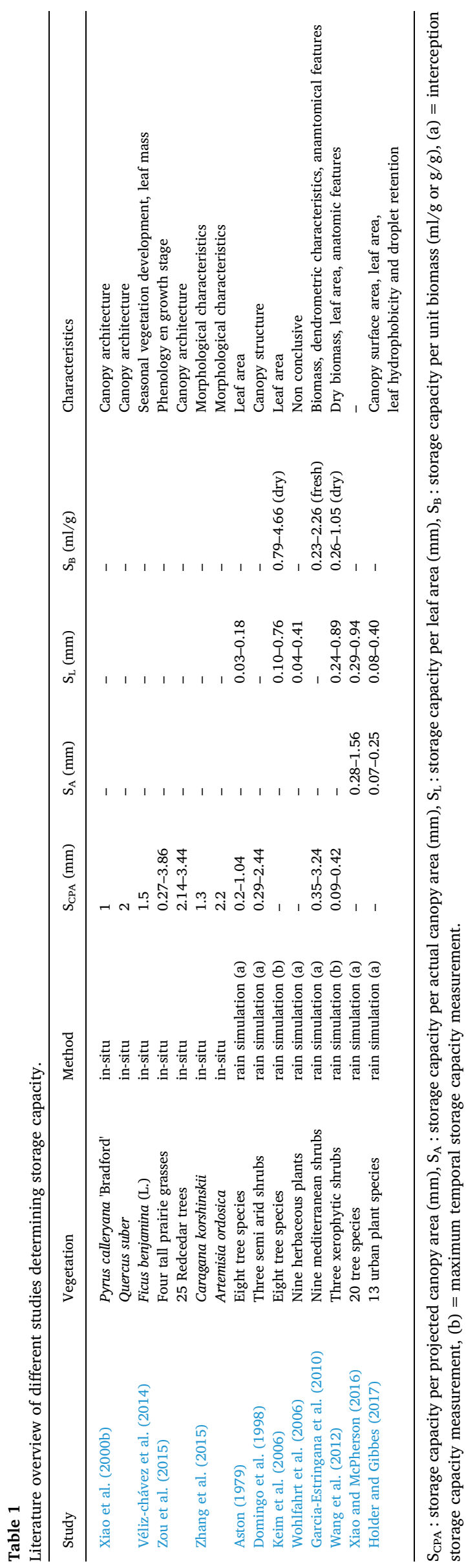


surface saturation- or minimum storage capacity (Xiao and McPherson, 2016) because this variable determines the quantity of rainwater that never reaches the ground surface and does not contribute to run-off. It is a vegetation characteristic largely independent from meteorological variables and is of great value for modelers to predict run-off volumes and rates during and after rain events. For simplicity, in what follows the static storage - or surface storage capacity will be referred to as the interception storage capacity.

Most authors that derived storage capacities tried to link those to certain vegetation characteristics. They then expressed this storage capacity as a function of the characteristic they thought of as most influential for storage capacity: The four main expressions of storage capacity are as a function of canopy projection area $\left(\mathrm{S}_{\mathrm{CPA}}, \mathrm{mm}\right)$ (e.g. Domingo et al., 1998; Garcia-Estringana et al., 2010; Wang et al., 2012), actual canopy area $\left(S_{A}, m m\right)$, which also includes the stem and branch surfaces (e.g. Holder and Gibbes, 2017; Xiao and McPherson, 2016), leaf area $\left(S_{L}, \mathrm{~mm}\right)$ (e.g. Keim et al., 2006; Wohlfahrt et al., 2006) and unit dry- or fresh biomass $\left(\mathrm{S}_{\mathrm{B}}, \mathrm{ml} / \mathrm{g}\right.$ or $\mathrm{g} / \mathrm{g}$ ) (e.g. Garcia-Estringana et al., 2010; Wang et al., 2012). Note that the interception storage capacities in $\mathrm{mm}$ are expressed on a reference area basis of one $\mathrm{m}^{2}$. Table 1 gives a literature overview of studies done on storage capacity.

Several other vegetation characteristics have been found to influence storage capacity besides the ones described above. These characteristics are mainly depending on canopy architecture or growth form (Pérez-Harguindeguy et al., 2013). The woody branch architecture of shrubs, having a canopy typically consisting of several diverging stems with secondary branches and leaves inserted in a certain angle results in densely covered ground area patches. This configuration giving rise to a large potential interception storage capacity. In a study featuring nine Mediterranean shrub species, Garcia-Estringana et al. (2010) found that the interception storage capacity of shrubs was largely determined by their morphology, particularly the branch- and leaf density were significant variables. He also found other morphological characteristics such as leaf hydrophobicity and pubescence, roughness of plant tissue and orientation of leaves and branches playing a role in water retention. Other green types such as common lawn and perennial grasses are herbaceous plants. Displaying no or very limited secondary growth and consisting primarily of soft tissue compared to woody plants, branchand leaf angles are not commonly measured for these vegetation types. A typical characteristic measured for grasses, known to influence interception storage capacity, is the percentage of vegetation cover over bare soil (e.g. Concilio et al., 2015). We hypothesize that the interception potential of small plant species is comparable or in some cases even higher than the one of solitary trees. The lack of standardization in expressing storage capacity values, together with the unclear definition of storage capacity itself which often has to be deduced from the context, makes comparing literature values challenging and should be done with caution. Moreover, most studies on small urban green plants were done on xerophytic species in a Mediterranean climate (GarciaEstringana et al., 2010; Wang et al., 2012), limiting applicability of their results in regions with a more temperate climate.

This study tries to generate reliable interception storage capacity data for several smaller urban plant species, common in temperate climate regions, by simulating rain events in a controlled environment and modelling interception storage capacity based on easy to measure vegetative characteristics. Generic models for predicting interception storage capacity within a species, as well as between species and between urban green types will be developed. Additionally, because biomass is an important vegetative characteristic and no standardized measuring procedure yet exists, models that estimate an individual plants' biomass are developed. These models can subsequently be used as input for the storage capacity models. Having models that accurately predict biomass and interception storage capacities of small urban plant species can greatly improve current urban hydrological models and help urban planners to make strategic decisions on where and what type of green to use.

The objectives of this study are threefold:

1) Measuring interception storage capacities of several small urban plant species by simulating rainfall events in controlled conditions and assessing their inter- and intra-species variability.

2) Construction of interception storage capacity models with data derived from objective 1 to determine vegetation characteristics within- and between species that significantly influence interception storage capacity.

3) Construction of biomass models, using vegetation characteristics easily measured in the field, to use as input for the interception storage capacity models.

\section{Material and methods}

\subsection{Species selection}

Four temperate climate species, of which two ground covering shrubs, a perennial grass and a grass mix commonly used for lawns were selected based on their different morphological characteristics, as well as their abundance in cities. The selected shrub species were Lonicera nitida 'Elegant' and Lavandula angustifolia 'Munstead'. The two grass species were the perennial grass Pennisetum alopecuroides 'Hameln' and a common grass mix used for lawn. Twelve individuals of each species, uniform in dimensions, were bought in a plant nursery. The species were planted in flower pots and were grown to cover most of their respective pot volumes. A polystyrene cover was made around the stem of $L$. nitida, L. angustifolia and P. alopecuroides to seal the substrate surface to prevent water infiltration during rainfall simulation. This cover was thoroughly waterproofed by applying epoxy resin where water could penetrate the substrate. The grass plots were bought in the form of pre-sowed mats with a substrate depth of $1.5-2 \mathrm{~cm}$ and cut into 12 identical pieces of $20 \times 35 \mathrm{~cm}$ (see Fig. 1).

L. nitida 'Elegant' (family: Caprifoliaceae) is a commonly used
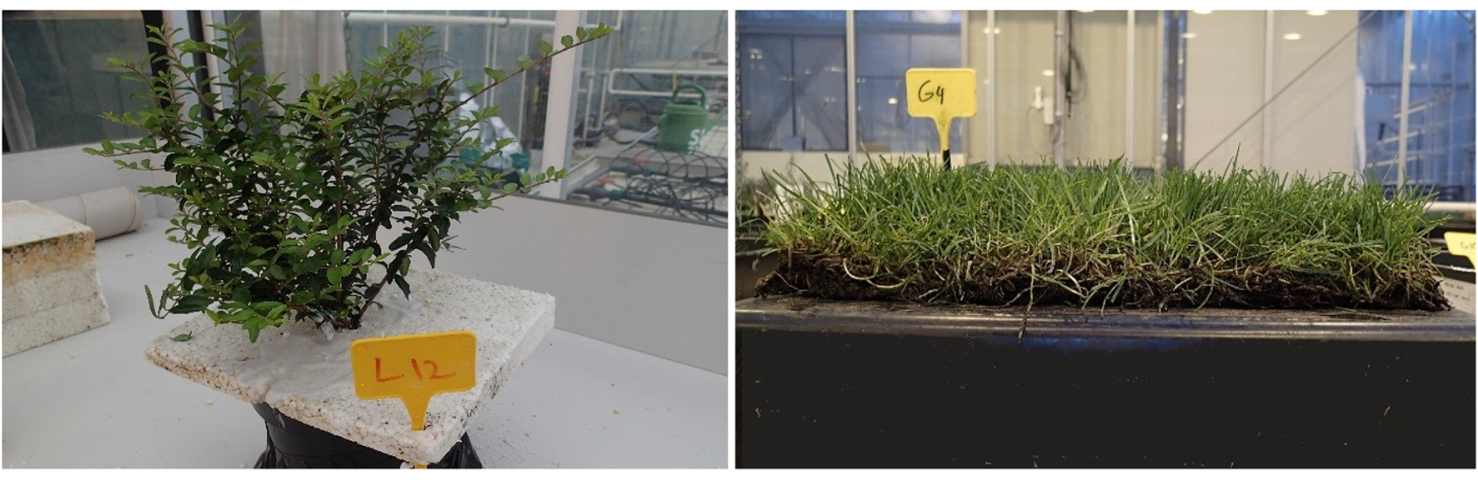

Fig. 1. Example of the polystyrene sheet covering the substrate (left) and the pre-sowed grass mats used (right). 
ground covering evergreen shrub typically reaching heights of $70-100 \mathrm{~cm}$. The species produces pairs of tabular, small creamy white flowers to $1 \mathrm{~cm}$ long from leaf axils from May until June and thrives in a wide range of climatological conditions, ranging from dry to wet areas and grows in both full sun and partial-shade. It originates from S.W. China. Partly due its good resistance to pollution, $L$. nitida is often planted in urban areas where it densely covers a ground surface consisting usually of several $\mathrm{m}^{2}$. Individual plants typically consist of one main stem, quickly diverging in multiple head branches. Its shiny, leathery ovate leaves are around $1.2 \mathrm{~cm}$ in length.

L. angustifolia 'Munstead' (family: Lamiaceae) is a common small, bushy evergreen shrub typically between 20 and $50 \mathrm{~cm}$ height. Its thin, linear, grey leaves range between 2 and $6 \mathrm{~cm}$. L. angustifolia produces unbranched stalks of fragrant, pale to deep purple flowers in dense spikes from June until August, which makes it an extremely popular plant in both public green and private gardens. It originates from the W. Mediterranean where it grows up to $1500 \mathrm{~m}$ a.s.L. The species is typically planted in dense patches covering the ground surface. It thrives in sunny conditions and in a well-drained dry to moist soil.

$P$. alopecuroides 'Hameln' (family: Poaceae) is a widely used ornamental compact clump-forming, wintergreen grass with arching, linear leaves, to about $20 \mathrm{~cm}$ long and plant size typically reach a height of $50-80 \mathrm{~cm}$. It's a dwarf cultivar of Chinese fountain grass that unlike the
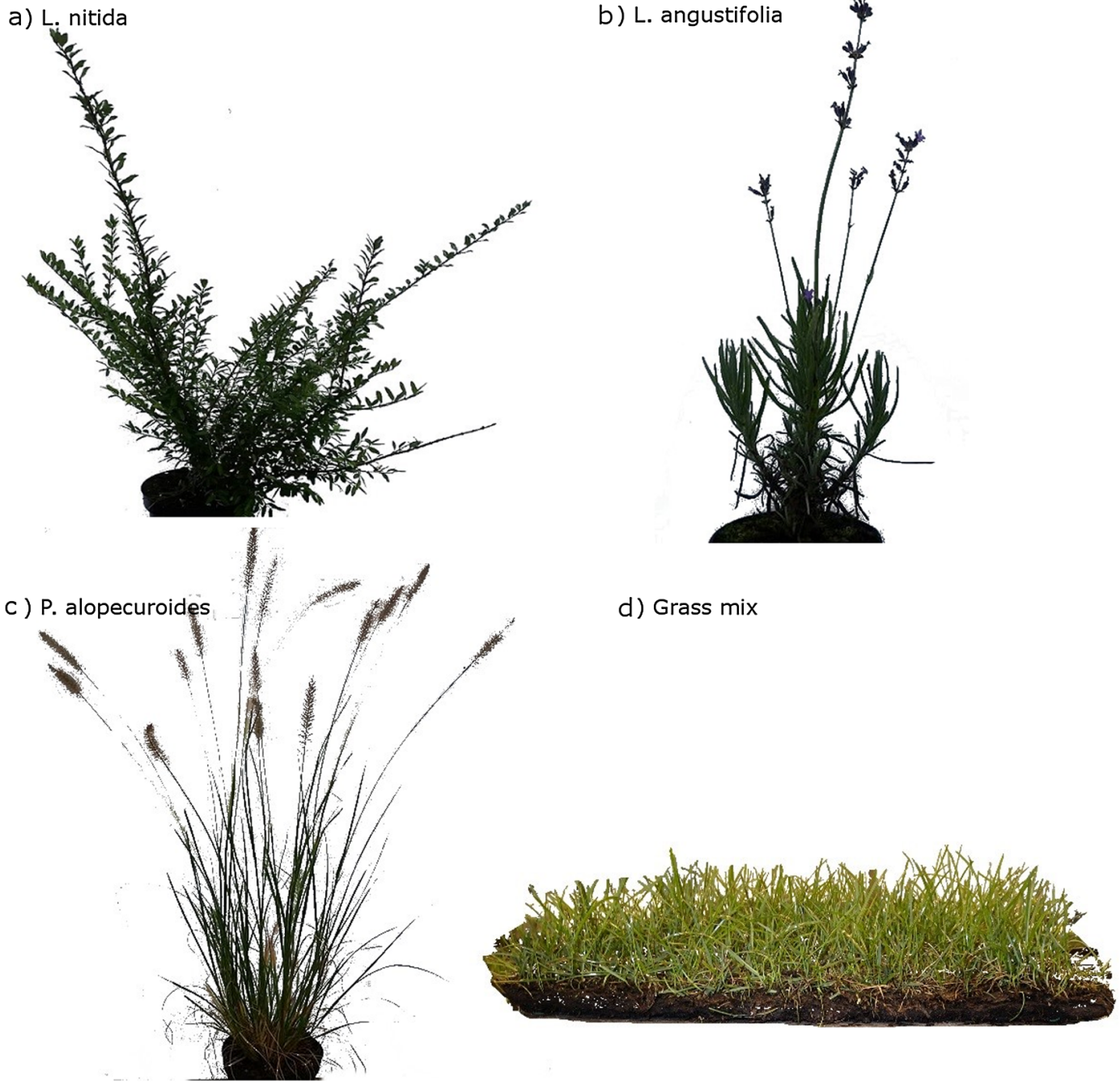

Fig. 2. Illustrative picture of species a) L. nitida, b) L. angustifolia, c) P. alopecuroides and d) grass mix.

original species re-seed itself. The light brown to greenish white flowers occur in a spike like inflorescence of about $12 \mathrm{~cm}$ long. P. alopecuroides originates from E. Asia to W. Australia and is widely naturalized in Europe and N. America. The species thrives in full sun to partial shade. It prefers a well-drained moist soil and is often planted in groups with individuals close to each other.

Common grass mixtures used for lawn vary in species composition. The mixture used in this research consists of three species: $45 \%$ Festuca rubra, 35\% Poa pratensis and 20\% Lolium perenne. Its height varies depending on when the lawn is mown. The maximum height of the grass used in this experiment was $9 \mathrm{~cm}$. Illustrative pictures of the species can be seen in Fig. 2.

\subsection{Statistical- and experimental design}

The workflow and experimental design of this study is depicted in Fig. 3:

At the start of the experiment all twelve plants of each species were of similar size and shape and showed little intra-species variation. This imposes problems for estimations of the parameters in the statistical models that will be developed to predict interception storage capacity and biomass. To be able to estimate all parameters accurately, larger differences in the vegetation characteristics influencing interception

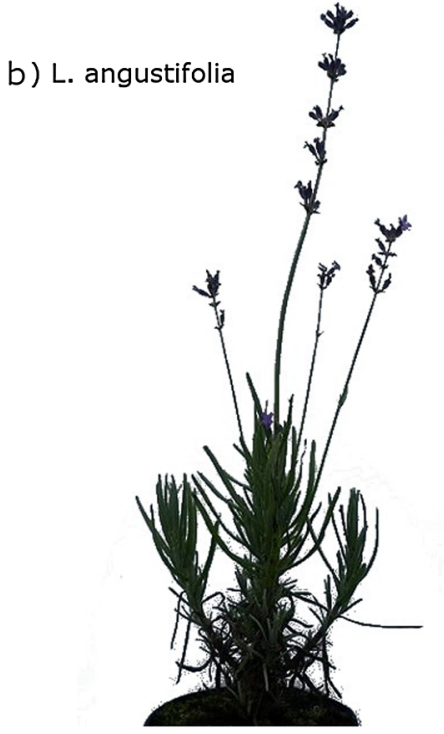

d) Grass mix 


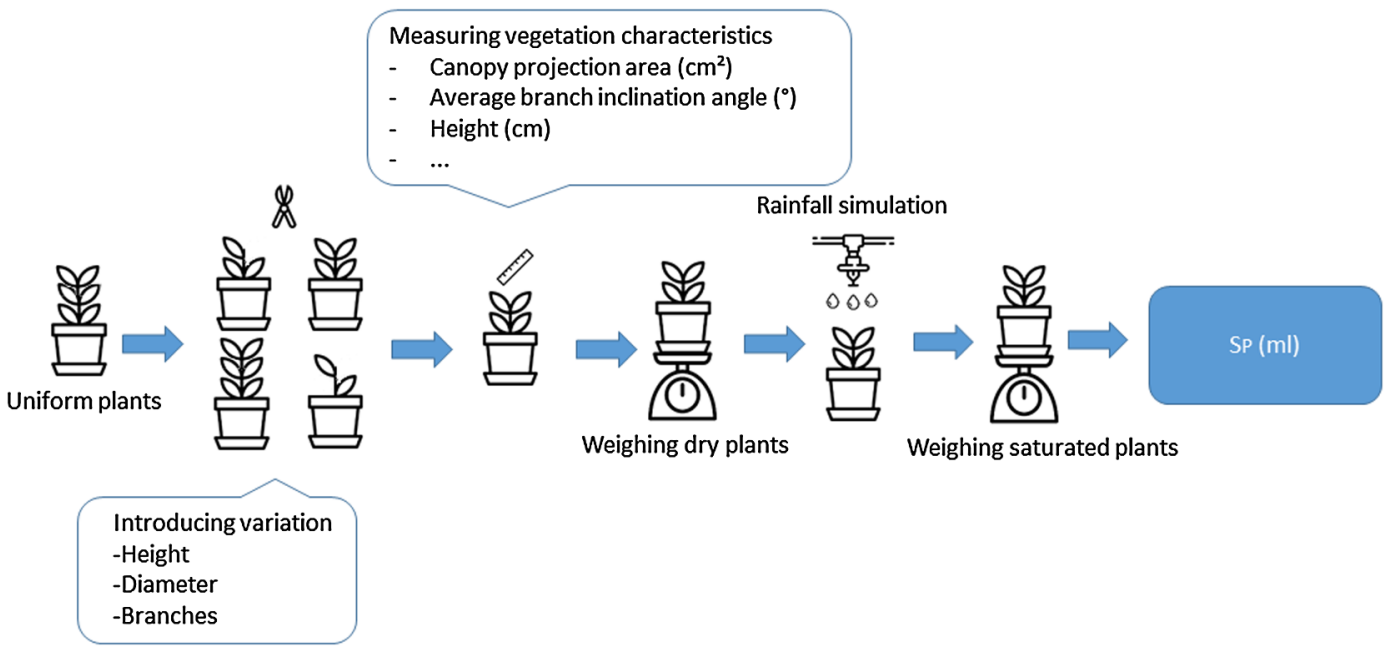

Fig. 3. Workflow and experimental design. The $S_{P}$ value $(\mathrm{ml})$ is derived directly from the experiments.

storage capacity were needed. Therefore a statistical method is presented to create maximal variation in a dataset of plant characteristics. These characteristics will then be used to construct multiple linear regression models that can be used to predict the interception storage capacity of each plant $\left(\mathrm{S}_{\mathrm{p}}, \mathrm{ml}\right)$ and the fresh biomass of each plant $\left(\mathrm{B}_{\mathrm{p}}\right.$, g). These two variables can then easily be converted to one of the common storage capacity measures in Table 1 . The procedure to do this can be consulted in Section 2.5.

Variation was introduced by means of pruning. To reduce the aliasing, this is the correlation between the characteristics due to the experimental design, as much as possible, a specific methodology was used. Traditionally, design of experiments was limited to choosing an appropriate design from a catalogue. The resulting designs were very inflexible regarding the number of runs and parameters to estimate. Because of the small number of observations and large number of characteristics, a more flexible approach of algorithmic experimental design or optimal experimental design was adopted. This design gives high flexibility regarding the number of runs and characteristics that can be of interest (Goos and Jones, 2011). In this case, a D-optimal design was constructed for each vegetation type. The D-optimality criterion minimizes the confidence ellipsoid on the parameter estimates by minimizing the determinant of the Fisher information matrix. As a result, parameters are estimated as precise as possible and aliasing is reduced to a maximum (Atkinson et al., 2007).

However, because several vegetation characteristics are interdependent, it was impossible to imply this design very strict. To overcome this, the following strategy was adopted. Firstly, one vegetation characteristic was selected. For this characteristic the plants were altered following the experimental design. Consequently, altering the plants impacted other vegetation characteristics. Secondly, another vegetation characteristic was selected and the plants were altered following the design. After all chosen characteristics were altered, a large variability was achieved, making it possible to estimate all parameters with as little aliasing as possible. The increased variation in the dataset is reflected as a higher coefficient of variation (CV). The CV is obtained by dividing the standard deviation by the absolute value of the mean and is used as a measure to show the extent of variability around the mean.

The altered characteristics were height, diameter and number of branches for both shrub species. For P. alopecuroides, the number of leaves and number of inflorescences were modified and for the grass mix the altered vegetation characteristics were height and cover. All these characteristics showed relatively high degrees of correlation, meaning that modifying one characteristic also influenced the other characteristics.

\subsection{Measured plant characteristics}

Most plant characteristics were measured according to the methods described in Pérez-Harguindeguy et al. (2013). For shrubs, the plant characteristics measured were: canopy projection area $\left(\mathrm{CPA}, \mathrm{m}^{2}\right)$, diameter $(\mathrm{d}, \mathrm{cm})$, average leaf inclination angle $\left(\mathrm{a}_{\mathrm{L}},{ }^{\circ}\right)$, average branch inclination angle $\left(\mathrm{a}_{\mathrm{B}},{ }^{\circ}\right)$, height $(\mathrm{h}, \mathrm{cm})$, leaf area index (LAI, -$)$ and $\mathrm{B}_{\mathrm{p}}$ $(\mathrm{g})$. The measured vegetation characteristics of the perennial grass, $P$. alopecuroides were CPA $\left(\mathrm{m}^{2}\right), \mathrm{h}(\mathrm{cm}), \mathrm{B}_{\mathrm{p}}(\mathrm{g})$ and number of brown inflorescences (f, -$)$. The characteristics measured of the grass mix were $\mathrm{h}(\mathrm{cm}), \mathrm{B}_{\mathrm{P}}(\mathrm{g})$ and cover $(\mathrm{c}, \%)$.

To calculate the CPA, a methodology similar to the one used by Garcia-Estringana et al. (2010) has been applied. A top down picture, consistently on the same height, was taken of each individual plant together with a $2 \times 2 \mathrm{~cm}$ reference surface. Digital image analysis software, SigmaScan Pro 5, was used to calculate the number of pixels of the reference surface (Fig. 4). Then the number of pixels containing green leaves was calculated by applying a color detection algorithm on the image. Because of the subtle differences in green between plant species, the hue and saturation values on which the color-algorithm depends had to be obtained through trial and error. Dividing the number of pixels recognized as leaves by the number of pixels of the reference surface and multiplying this number by the reference surface $\left(4 \mathrm{~cm}^{2}\right)$, resulted in the CPA of the plant.

To determine $a_{L}, 20$ randomly chosen leaves of each individual distributed over the whole plant were measured. Only leaves positioned perpendicular to the camera were used. A horizontal picture was taken and the angles were measured with the program MB-ruler (http:// www.markus-bader.de/MB-Ruler/index.php). The same procedure was applied to measure $\mathrm{a}_{\mathrm{B}}$. All main branch angles perpendicular to the photograph of each individual were measured. Using a tape, $h$ was obtained by measuring from the polystyrene base covering the substrate to the top of the plant. To determine the LAI of shrubs, a new, fast and accurate procedure was developed. Sixty random branches of each species were measured and divided in three length classes: short, middle and long. Next, five branches of each class were dissected and the average leaf area $\left(\mathrm{cm}^{2}\right)$ of each branch length-class was calculated with SigmaScan Pro 5, using the pixel-color identification algorithm discussed before. On each plant, the number of short, middle and long branches were manually counted and multiplied by the average leaf area of each class, resulting in the approximated total leaf area $\left(\mathrm{cm}^{2}\right)$ of the plant. This value was then divided by its CPA, which resulted in the LAI. The plants' biomass $\left(\mathrm{B}_{\mathrm{P}}\right)$ was measured with a scale (Sartorius L2200P, precision $0.01 \mathrm{~g}$ for $L$. nitida and $L$. angustifolia and Mettler PJ6000, precision $0.1 \mathrm{~g}$ for P. alopecuroides and the grass mix) after 


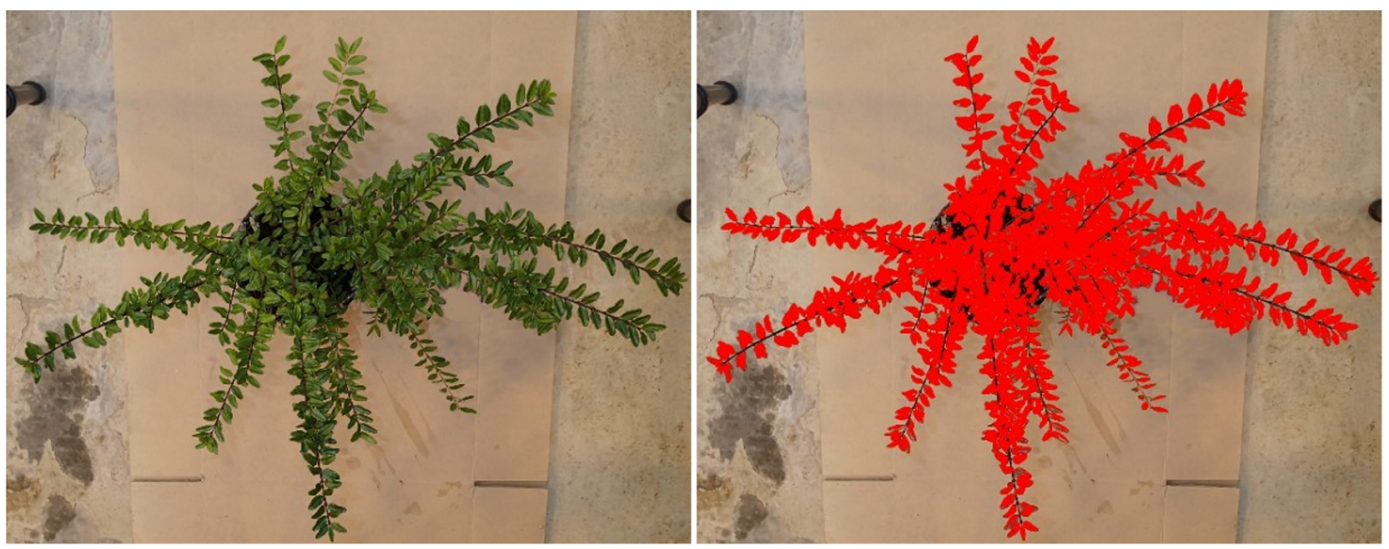

Fig. 4. Example of the color detection algorithm before (left) and after (right) application, used in Sigmascan Pro 5 to calculate canopy projection area ( $\mathrm{m}^{2}$ ).

cutting the plant at its base when the rainfall simulator experiments had finished. $P$. alopecuroides and the grass mix required a different scale with a higher measurement range $(0.1-6000 \mathrm{~g}$ in comparison to $0.01-2220 \mathrm{~g}$ for $L$. nitida and $L$. angustifolia) because of their higher weight. The number of inflorescences (f) was manually counted for each individual of $P$. alopecuroides. The cover (c) of each grass mix plot was found by applying the same color detection algorithm used to determine the CPA of the shrubs. In this case the algorithm differentiated between grass - and bare soil pixels. The grass mix leaves' bend over sideways, hanging over the edges of the plots which sometimes resulted in cover percentage over $100 \%$.

\subsection{Rainfall simulation}

After modifying the vegetation characteristics as described in the statistical- and experimental design section, each plant was weighed and placed in a random design on a tray table in a climate controlled greenhouse. Air temperature and air humidity ranges in the greenhouse were kept steady during and after rain events between 23.9 and $25.7^{\circ} \mathrm{C}$ and $50-71.5 \%$ respectively.

Once all plants were placed on the tray table, a rainfall event using the greenhouse's sprinkler system was simulated. This system consisted of polyamide arc sprinklers with a nozzle diameter of $2.25 \mathrm{~mm}$. At a pressure of $2 \mathrm{bar}$, these sprinklers generate a flow rate of $2.75 \mathrm{~L} / \mathrm{min}$ in a radius of $1.6 \mathrm{~m}$. This equates to an average rain intensity of $20.5 \mathrm{~mm} /$ $\mathrm{h}$. The expected median diameter of the drop size was between 0.68 and $1.09 \mathrm{~mm}$, based on Kincaid et al. (1996) in which a similar sprinkler system was applied with the same nozzle diameter and water pressure as in this study. After 15-20 min, once the vegetation was fully saturated, the sprinkler system was turned off and the plants were left to drip for two minutes, after which they were weighed again. The long simulation time made sure that the vegetation was fully saturated and the amount of water retained corresponded to the full interception storage capacity of the plant, as previously demonstrated by Keim et al. (2006) who found that water stored on branches came to equilibrium within 5-10 min at a rainfall intensity of $20 \mathrm{~mm} / \mathrm{h}$. By then subtracting the plant's dry weight from the weight of the wet plants, the interception storage capacity was determined. This method was previously used by Garcia-Estringana et al. (2010) and Wang et al. (2012).

The procedure used for the grass mix plots was slightly different because they were bought in the form of pre-sown mats with a substrate depth of $1.5-2 \mathrm{~cm}$. The substrate was saturated first by submersion in a water basin with a water level just high enough to submerge the substrate, but not the vegetation. After the substrate was fully saturated the grass mix plots were taken out the basin and placed on a tray table in the greenhouse and rainfall simulation commenced. The storage capacity was then calculated by subtracting the weight of the fully saturated grass plots from the plots where only the substrate was saturated.

\subsection{Storage capacity measures}

The storage capacity of each plant $\left(\mathrm{S}_{\mathrm{p}}\right)$, as directly measured in the rainfall simulation experiments, was converted into two additional measures of storage capacity. Firstly a conversion was made to $S_{B}$ by dividing by the plants' biomass $\left(S_{B}=S_{p} / B_{p}\right)$. Secondly, by multiplying $\mathrm{S}_{\mathrm{B}}$ with the biomass present in one $\mathrm{m}^{2}\left(\mathrm{~B}_{\mathrm{CPA}}, \mathrm{kg} / \mathrm{m}^{2}\right), \mathrm{S}_{\mathrm{CPA}}$ was found $\left(\mathrm{S}_{\mathrm{CPA}}=\mathrm{S}_{\mathrm{B}}{ }^{*} \mathrm{~B}_{\mathrm{CPA}}\right)$. To calculate the biomass present in one $\mathrm{m}^{2}\left(\mathrm{~B}_{\mathrm{CPA}}\right)$, the plant density (no. plants $/ \mathrm{m}^{2}$ ) was estimated using the CPA $\left(\mathrm{m}^{2}\right)$ of each individual (no. plants $/ \mathrm{m}^{2}=1 / \mathrm{CPA}$ and $\mathrm{B}_{\mathrm{CPA}}=$ no. plants $/ \mathrm{m}^{2} *$ $\mathrm{B}_{\mathrm{p}}$ ). This method of upscaling was used by Garcia-Estringana et al. (2010) and Wang et al. (2012) among others. The reason why was opted for $\mathrm{S}_{\mathrm{CPA}}$, and not for the $\mathrm{S}_{\mathrm{L}}$ or $\mathrm{S}_{\mathrm{A}}$ is that all in-situ studies make use of $S_{\mathrm{CPA}}$ (Table 1). By using the same method of expressing interception storage capacity as the experiments done in field conditions, the results obtained are more comparable and transferable to outdoor situations.

To summarize, three different interception storage capacity measures are used: 1 ) storage capacity of each plant $\left.\left(\mathrm{S}_{\mathrm{p}}, \mathrm{ml}\right), 2\right)$ storage capacity per unit biomass $\left(\mathrm{S}_{\mathrm{B}}, \mathrm{ml} / \mathrm{g}\right)$ and 3 ) storage capacity based on canopy projection area $\left(\mathrm{S}_{\mathrm{CPA}}, \mathrm{mm}\right)$.

After all interception storage capacities were calculated, an initial outlier detection was done using Tukey boxplots (McGill et al., 1978). This method makes no assumptions about data distribution and is applicable to both normal- and skewed distributed data. After detection, the extreme values were interpreted and a decision was made whether to remove them. Next, model construction commenced.

\subsection{Model construction}

Predictive models were developed for $S_{p}$ and $B_{p}$. The model construction workflow chart is depicted in Fig. 5:

To assess the level of correlation between the vegetation characteristics, a Principal Component Analysis (PCA) was performed. Next to that, the Spearman correlation between all pairs of characteristics was calculated. This correlation is the sum of multicollinearity or interdependence of the characteristics on the one hand, and the aliasing or correlation introduced by the experimental design on the other hand. When high correlations are present, model selection becomes increasingly difficult and calculated p-values for each estimated parameters become ambiguous. As a rule of thumb, a Spearman correlation $>0.80$ is regarded as troublesome (Neter et al., 2004). When two characteristics were deemed too correlated, practical considerations such as easiness to measure, decided which characteristic was kept in the modelling procedure.

Subsequently, the same paradigm was used for the $S_{p}$ and $B_{p}$ models to perform the statistical analysis. After the first outlier detection using Tuckey boxplots, the dependent variables were Log-transformed and 


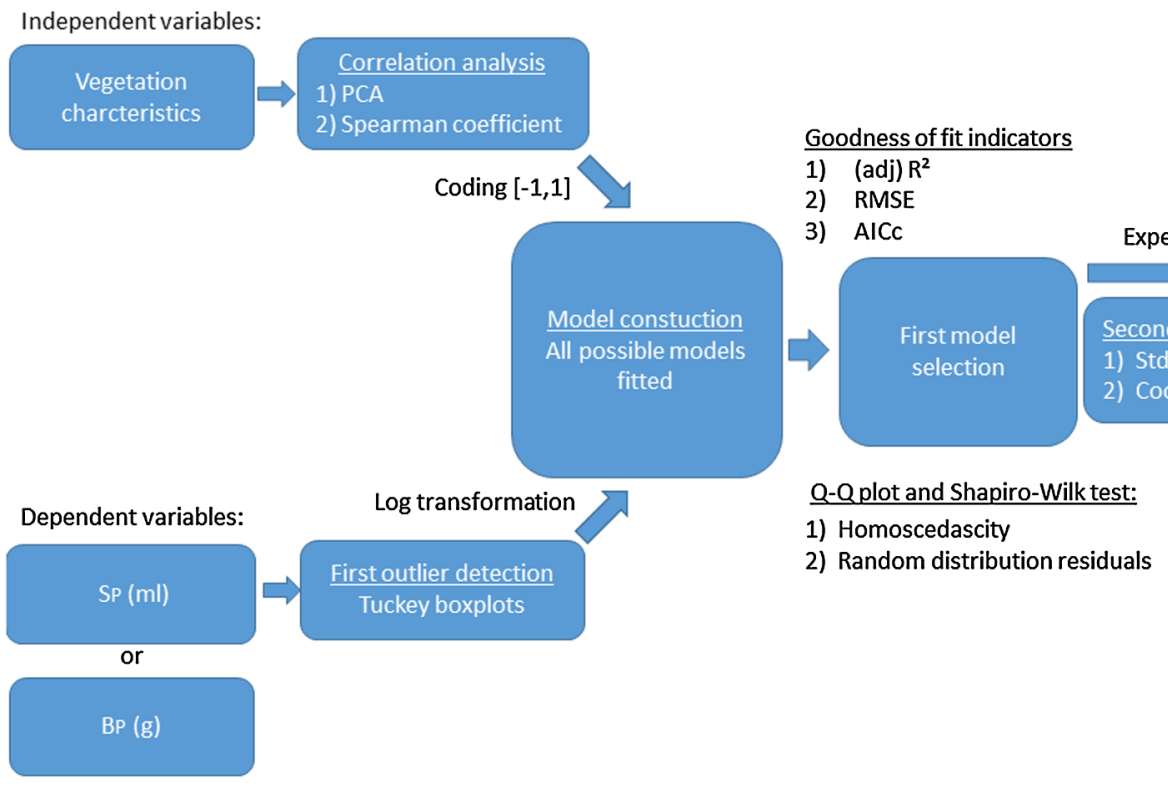

Fig. 5. Workflow and statistical methods used to construct multiple linear regression models to predict $S_{P}(\mathrm{ml})$ and $B_{P}(g)$.

based on Multiple Linear Regression, all possible models were fitted. For these models, the vegetation characteristics and all second-order interactions and quadratic effects of these characteristics are used as independent variables. To reduce present multicollinearity as much as possible and remove any scale effects in the estimates, all vegetation characteristics were coded to fall in the range $[-1,1]$. The first model selection was based on the goodness-of-fit statistics R2, adjusted R2, the Root Mean Squared Error (RMSE) and the corrected Akaike's Information Criterion (AICc). The Akaike's information criterion gives a score to a model based on its goodness of fit and complexity, it is a comparative criterion and its value is only meaningful relative to other values. The corrected version of the criterion takes into account finite sample sizes and is especially useful for smaller sample sizes such as in this research. When several models performed equally good, the simplest model with the least variables and interactions was chosen.

During the first model selection, normality of the residuals was checked qualitatively by means of a quantile plot (QQ-plot) and more formally with a Shapiro-Wilk test. To test homoscedasity or constant variance of the residuals, the studentized residuals, which is the ratio of a residual over its standard deviation, are plotted in function of the predicted values. The same plot was used to make sure that the residuals are randomly distributed and no outliers are present in the model. As a final outlier detection method, Cook's D values are calculated for all observations to assess the influence or leverage of each observation. If an observation had a Cook's D value $>4 / n$, and a studentized residual value $>2$ (Neter et al., 2004), it was flagged as outlier and excluded from further analysis. When all assumptions are met and there no more outliers were present, the chosen model was refitted and discussed.

For the models encompassing more than one species, an extra species variable 'i' was introduced. This qualitative variable assigns a different value to each species in the model and accounts for the variance in storage capacity attributable to a specific species. In other words, the species variable accounts for variance that is not found by measuring the plant characteristics, as described in Section 2.3, but is still present. For the models where the species variable 'i' turned out to be a significant addition, a conversion was done to a mixed model. In this type of model, the plant species was regarded as being a random pick from a population of possible plant species. As such there is a variance component estimated for the entire species population. The larger the species effect, the more difficult it will be to do accurate interception storage capacity predictions for other plant species. This way the species effect is an indicator of the generic applicability of the model.
Doing this conversion increases the scope of the model from only the species in the experiment to all possible species of that vegetation type.

To validate the final model, the predicted residual error sum of squares (PRESS) was chosen. This often used leave-one-out cross validation statistic refits the model several times, leaving out one observation and refitting the model with the remaining observations. The resulting model is then used to estimate the excluded observation and the prediction error is determined. After all prediction errors are determined, the PRESS is calculated as the sum of squares of all these errors (Neter et al., 2004). A lower PRESS indicates a better model. Like the Akaike's information criterion, the resulting PRESS value is only meaningful when comparing different models among each other and its value has no inherent meaning on its own.

Finally, when all $B_{P}$ and $S_{P}$ models were constructed, a reverse $S_{P}$ estimation was done by using the output of $B_{P}$ models as input for the $S_{P}$ models. This allowed for a comparison between the measured results in the rainfall experiments and the estimated results obtained through the modelling procedure. The average-, average absolute-, median absolute-, minimum- and maximum error between the measured and predicted $S_{P}$ values was calculated.

\section{Results}

\subsection{Vegetation characteristics}

The original- and modified mean values of the plant characteristics of every species can be found in Table 2 together with their coefficient of variation (CV).

As can be seen in Table 2 the CV of all modified vegetation characteristics increased, indicating that through the statistical design presented in this study a larger variation has been created in the dataset.

The mean of the measured vegetation characteristics per species, after modification of the above described variables, are presented with their standard deviation in Table 3.

The differences in CPA and $\mathrm{B}_{\mathrm{p}}$ are mainly attributable to the different dimensions of the urban plant species. Remarkable differences were found in $\mathrm{a}_{\mathrm{L}}$ between the two shrub species. L. nitida has nearly horizontal leaves ( $4 \pm 6.7^{\circ}$ ), while $L$. angustifolia has its leaves oriented in a much steeper, upright angle $\left(45.7 \pm 14.8^{\circ}\right)$. Besides the steeper average leaf angle, $L$. angustifolia has an LAI $>4$ times as large as $L$. nitida and its branches are oriented in a steeper angle at an orientation of $70.6 \pm 7^{\circ}$ in comparison with $L$. nitida that has an $\mathrm{a}_{\mathrm{B}}$ of $46.5+-8.3^{\circ}$. 
Table 2

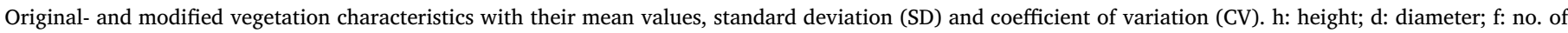
inflorescences; c: cover.

\begin{tabular}{|c|c|c|c|c|c|c|}
\hline Species & $\mathrm{n}$ & Characteristic & Original mean $+\mathrm{SD}$ & Modified mean + SD & Original CV & Modified CV \\
\hline \multirow[t]{3}{*}{ L. nitida } & 12 & $\mathrm{~h}(\mathrm{~cm})$ & $30.3 \pm 4.8$ & $24 \pm 5.9$ & $15.8 \%$ & $24.6 \%$ \\
\hline & 12 & $\mathrm{~d}(\mathrm{~cm})$ & $46.9 \pm 4$ & $30.3 \pm 14.4$ & $8.5 \%$ & $47.5 \%$ \\
\hline & 12 & branches (\#) & $14.4 \pm 5.8$ & $11 \pm 5$ & $40.3 \%$ & $45.5 \%$ \\
\hline \multirow[t]{3}{*}{ L. angustifolia } & 12 & $\mathrm{~h}(\mathrm{~cm})$ & $18.5 \pm 5.1$ & $11.6 \pm 4$ & $27.6 \%$ & $34.5 \%$ \\
\hline & 12 & $\mathrm{~d}(\mathrm{~cm})$ & $15 \pm 1.9$ & $11.3 \pm 2$ & $12.7 \%$ & $17.7 \%$ \\
\hline & 12 & branches(\#) & $12.8 \pm 2$ & $8 \pm 4$ & $15.6 \%$ & $50.0 \%$ \\
\hline \multirow[t]{2}{*}{ P. alopecuroides } & 12 & leaves $(\#)$ & $43.4 \pm 9$ & $32 \pm 10$ & $20.7 \%$ & $31.3 \%$ \\
\hline & 12 & $\mathrm{f}(\#)$ & $17.7 \pm 9$ & $15 \pm 8$ & $50.9 \%$ & $53.3 \%$ \\
\hline \multirow[t]{2}{*}{ Grass mix } & 12 & $\mathrm{~h}(\mathrm{~cm})$ & $8.6 \pm 1.16$ & $6.2 \pm 2.6$ & $13.5 \%$ & $41.9 \%$ \\
\hline & 12 & c (\%) & $107.9 \pm 8.2^{*}$ & $102.1+-10.6$ & $7.6 \%$ & $10.4 \%$ \\
\hline
\end{tabular}

* : value based on 5 grass plots.

Table 3

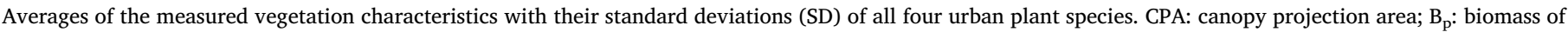
each plant; $\mathrm{B}_{\mathrm{CPA}}$ : biomass per $\mathrm{m}^{2}$; h: height; $\mathrm{a}_{\mathrm{L}}$ : average leaf angle; LAI: leaf area index; $\mathrm{a}_{\mathrm{B}}$ : average branch angle; f: no. of inflorescences; $\mathrm{c}$ : cover.

\begin{tabular}{|c|c|c|c|c|}
\hline characteristic & L. nitida ( $\mathrm{n}=12$ ) & L. angustifolia $(\mathrm{n}=12)$ & P. alopecuroides $(\mathrm{n}=12)$ & Grass mix $(n=12)$ \\
\hline $\mathrm{CPA}\left(\mathrm{cm}^{2}\right)$ & $562 \pm 141$ & $57 \pm 25$ & $330 \pm 85$ & $715 \pm 74$ \\
\hline$B_{p}(g)$ & $45.93 \pm 11.3$ & $13.57 \pm 3.96$ & $123.1 \pm 21.69$ & $78.9 \pm 15.47$ \\
\hline $\mathrm{B}_{\mathrm{CPA}}(\mathrm{kg})$ & $0.824 \pm 0.126$ & $2.525 \pm 0.639$ & $4.04 \pm 1.58$ & $1.10 \pm 0.17$ \\
\hline $\mathrm{h}(\mathrm{cm})$ & $24 \pm 5.9$ & $11.6+-4$ & $59.2 \pm 3.9$ & $6.2 \pm 2.6$ \\
\hline $\mathrm{a}_{\mathrm{L}}\left({ }^{\circ}\right)$ & $4 \pm 6.7$ & $45.7+-14.8$ & - & - \\
\hline LAI $(-)$ & $1 \pm 0.04$ & $4.32 \pm 0.52$ & - & - \\
\hline $\mathrm{a}_{\mathrm{B}}\left({ }^{\circ}\right)$ & $46.5 \pm 8.3$ & $70.6 \pm 7$ & - & - \\
\hline$f(-)$ & - & - & $15 \pm 8$ & - \\
\hline c (\%) & - & - & - & $102.1 \pm 10.6$ \\
\hline
\end{tabular}

\subsection{Storage capacities}

A visual representation of the three storage capacity measures can be seen in the Tukey boxplots in Fig. 6.

As can be seen in Fig. 6, outliers are present in each method of expressing storage capacity. L. nitida has the same outlier present in all three types of storage capacity. $L$. angustifolia has the same outlier in $S_{B}$ and in $S_{C P A}$. The grass mix has one outlier in the $S_{B}$ approach. Because these values are deemed unrealistically high in comparison to the other values of these species, they are assumed to be measurement errors and are excluded from the modelling part.

Table 4 shows the mean storage capacities per species.

The relatively large standard deviations of average storage capacity values reflect the variation imposed on the dataset in the experimental design. This created variation will be used to construct multiple linear regression models with $S_{\mathrm{P}}(\mathrm{ml})$ as dependent variable. Some noticeable
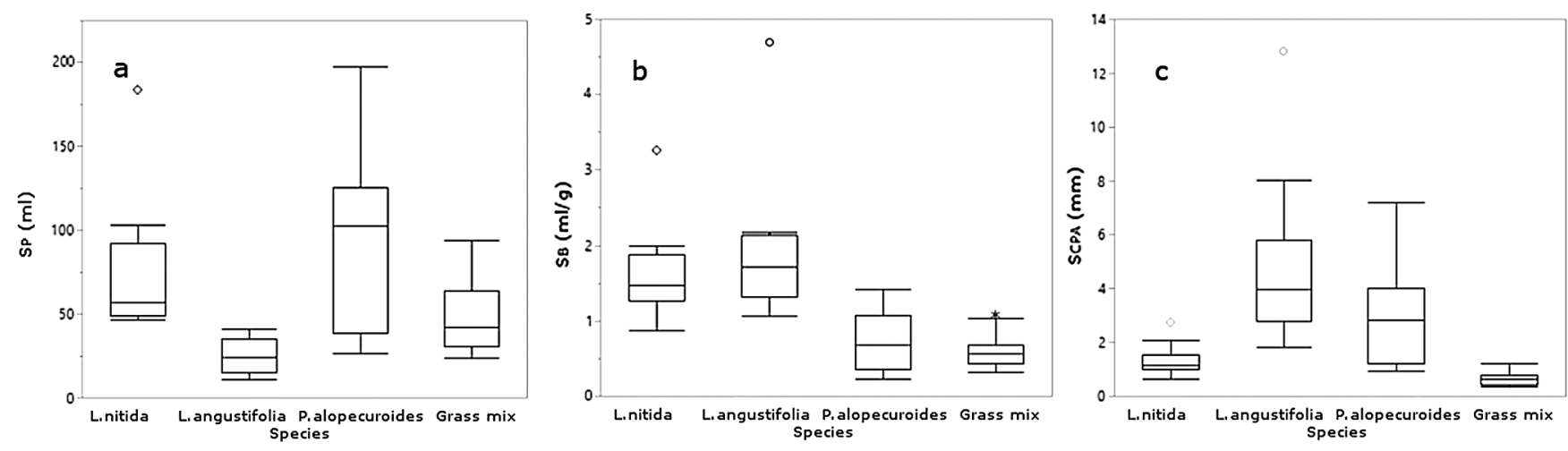

Fig. 6. Boxplots showing outliers for each storage capacity measure. a) $S_{P}(\mathrm{ml})$, b) $S_{B}(\mathrm{ml} / \mathrm{g})$ and c) $S_{C P A}(\mathrm{~mm})$.

Table 4

Means storage capacities with their standard deviations (SD). $\mathrm{n}$ is the number of individuals, outliers excluded. $\mathrm{S}_{\mathrm{P}}$ : storage capacity for each plant (ml); $\mathrm{S}_{\mathrm{B}}$ : storage capacity per unit biomass $(\mathrm{ml} / \mathrm{g})$; $\mathrm{S}_{\mathrm{CPA}}$ : storage capacity based on canopy projection area $(\mathrm{mm})$.

\begin{tabular}{|c|c|c|c|c|c|c|c|c|c|}
\hline Species & $\mathrm{n}$ & $\mathrm{S}_{\mathrm{P}}(\mathrm{ml})$ & SD & $\mathrm{n}$ & $\mathrm{S}_{\mathrm{B}}(\mathrm{ml} / \mathrm{g})$ & SD & $\mathrm{n}$ & $\mathrm{S}_{\mathrm{CPA}}(\mathrm{mm})$ & SD \\
\hline L. nitida & 11 & 64.93 & \pm 20.77 & 11 & 1.46 & \pm 0.35 & 11 & 1.21 & \pm 0.39 \\
\hline L. angustifolia & 12 & 24.89 & \pm 10.31 & 11 & 1.64 & \pm 0.41 & 11 & 4.22 & \pm 1.83 \\
\hline P. alopecuroides & 12 & 98.71 & \pm 51.17 & 12 & 0.75 & \pm 0.41 & 12 & 2.97 & \pm 1.89 \\
\hline Grass mix & 12 & 48.88 & \pm 22.08 & 11 & 0.57 & \pm 0.19 & 12 & 0.67 & \pm 0.26 \\
\hline
\end{tabular}


differences can be found between the three measures of storage capacity: the lowest mean $\mathrm{S}_{\mathrm{P}}$ can be found for L. angustifolia. When compensated for biomass, L. angustifolia has the highest storage capacity $\left(\mathrm{S}_{\mathrm{B}}\right)$. Due to its dense vegetation structure $L$. angustifolia holds more water per gram biomass than L. nitida. Another noticeable difference is that both grass species, in terms of $S_{B}$, have smaller storage capacities than the shrub species. Both grasses have average storage capacities $<1 \mathrm{ml} / \mathrm{g}$ while the storage capacities of L. nitida and $L$. angustifolia are $1.46 \pm 0.35 \mathrm{ml} / \mathrm{g}$ and $1.64 \pm 0.41 \mathrm{ml} / \mathrm{g}$ respectively.

Comparing the values of $\mathrm{S}_{\mathrm{CPA}}$, L. angustifolia has a very large interception storage capacity with an average value of $4.22 \pm 1.83 \mathrm{~mm}$. The second highest interception storage capacity is found in $P$. alopecuroides with $2.97 \pm 1.89 \mathrm{~mm}$, followed by $L$. nitida and the grass mix with interception storage capacity values of $1.21 \pm 0.39$ and $0.67 \pm 0.26 \mathrm{~mm}$ respectively.

\subsection{Modelling}

This section presents different fixed multiple linear regression models for $\mathrm{S}_{\mathrm{P}}(\mathrm{ml})$ and $\mathrm{B}_{\mathrm{p}}(\mathrm{g})$, constructed with the vegetation characteristics as independent variables.

\subsubsection{Storage capacity models $S_{P}(\mathrm{ml})$}

Table 5 and Fig. 7 show the models made with $S_{p}(\mathrm{ml})$ as dependent variable. Table 6 shows models 5 and 6 after conversion to a mixed model, using the same variables but assigning a random effect to the variable ' $i$ '. The prediction equations can be consulted in the attachments.

Models 1-4 are one-species models constructed for each species seperately. The shrub model is a two- species model construced with $L$. nitida and $L$. angustifolia and the all species model is a model were a regression is made using the four species used in this research. Both multiple species models have an qualitative species variable ' $i$ ', which assigns a number (1-4) to each species, taking in to account the species effect on the interception storage capacity. When two variables have a significant interaction effect, this is represented as a ' + ' in the table. When the interaction between two variables is significant, this means that their product makes a significant contribution to the model. When this effect is significant and added to the model, the separate variables of which the interaction is composed, need also to be kept in the model, even if they are not significant. This is known as the heredity principle.

One outlier was found for the L. angustifolia model with a Cook's $\mathrm{D}>4 / \mathrm{n}$ and a studentized residual $>2$. This value was excluded from further modelling and is depicted by the symbol ' $x$ ' in the actualby predicted plot 2 of Fig. 7 The reason for this exceptional value is considered to be a measurement inaccuracy during the weighing after the rainfall simulation experiments. This data point was subsequently excluded from the other models including this point, namely the shruband all species models. As can be seen from Table 5, the species effect (i) is significant in both the shrub- and all species models. This means $S_{P}$ (ml) is significantly influenced by the plant species for both models.

Biomass is the most important predictor variable determining $S_{P}$ for

Table 5

Multiple linear regression models for each species separately (model 1-4), both shrubs - L. nitida and L. angustifolia (model 5) and all species together (model 6) with $\mathrm{S}_{\mathrm{P}}(\mathrm{ml})$ as dependent variable.

\begin{tabular}{|c|c|c|c|c|c|c|c|c|}
\hline Number & Model & $\mathrm{n}$ & Variables & $\mathrm{R}^{2}$ & $\mathrm{R}^{2}$ adj & RMSE & ANOVA & PRESS \\
\hline 1 & L. nitida & 11 & $\mathrm{~B}_{\mathrm{P}}^{* *}, \mathrm{a}_{\mathrm{B}}{ }^{*}, \mathrm{~B}_{\mathrm{P}}+\mathrm{a}_{\mathrm{B}}{ }^{*}$ & 0.61 & 0.44 & 0.22 & $<0.1$ & 0.74 \\
\hline 2 & L. angustifolia & 11 & $\mathrm{~B}_{\mathrm{P}} * * *$ & 0.59 & 0.55 & 0.28 & $<0.1$ & 1.76 \\
\hline 3 & P. alopecuroides & 12 & $\mathrm{~B}_{\mathrm{P}}{ }^{* *}, \mathrm{CPA}^{* *}, \mathrm{~h}^{* *}, \mathrm{CPA}+\mathrm{h}^{* *}$ & 0.63 & 0.42 & 0.5 & $<0.1$ & 7.94 \\
\hline 4 & Grass mix & 12 & $\mathrm{~B}_{\mathrm{P}}^{* *}$ & 0.34 & 0.27 & 0.37 & $<0.05$ & 2.29 \\
\hline 5 & Shrub model & 22 & $B_{P}^{* * *}, i^{* * *}, B_{P}+i^{* * *}$ & 0.85 & 0.82 & 0.27 & $<0.001$ & 2.64 \\
\hline 6 & All species & 46 & $\mathrm{~B}_{\mathrm{P}}^{* * *}, \mathrm{i}^{* * *}$ & 0.62 & 0.58 & 0.43 & $<0.001$ & 9.78 \\
\hline
\end{tabular}

Variables: $\mathrm{B}_{\mathrm{P}}=$ biomass $(\mathrm{g}), \mathrm{a}_{\mathrm{B}}=$ average branch angle $\left({ }^{\circ}\right), \mathrm{CPA}=$ Canopy projection area $\left(\mathrm{m}^{2}\right), \mathrm{h}=$ height $(\mathrm{cm}), \mathrm{i}=$ species variable $*=\mathrm{p}<0.10, * *=\mathrm{p}<0.05, * * *=\mathrm{p}<0.01$, n.s. $=$ not significant, $+=$ interaction between variables.
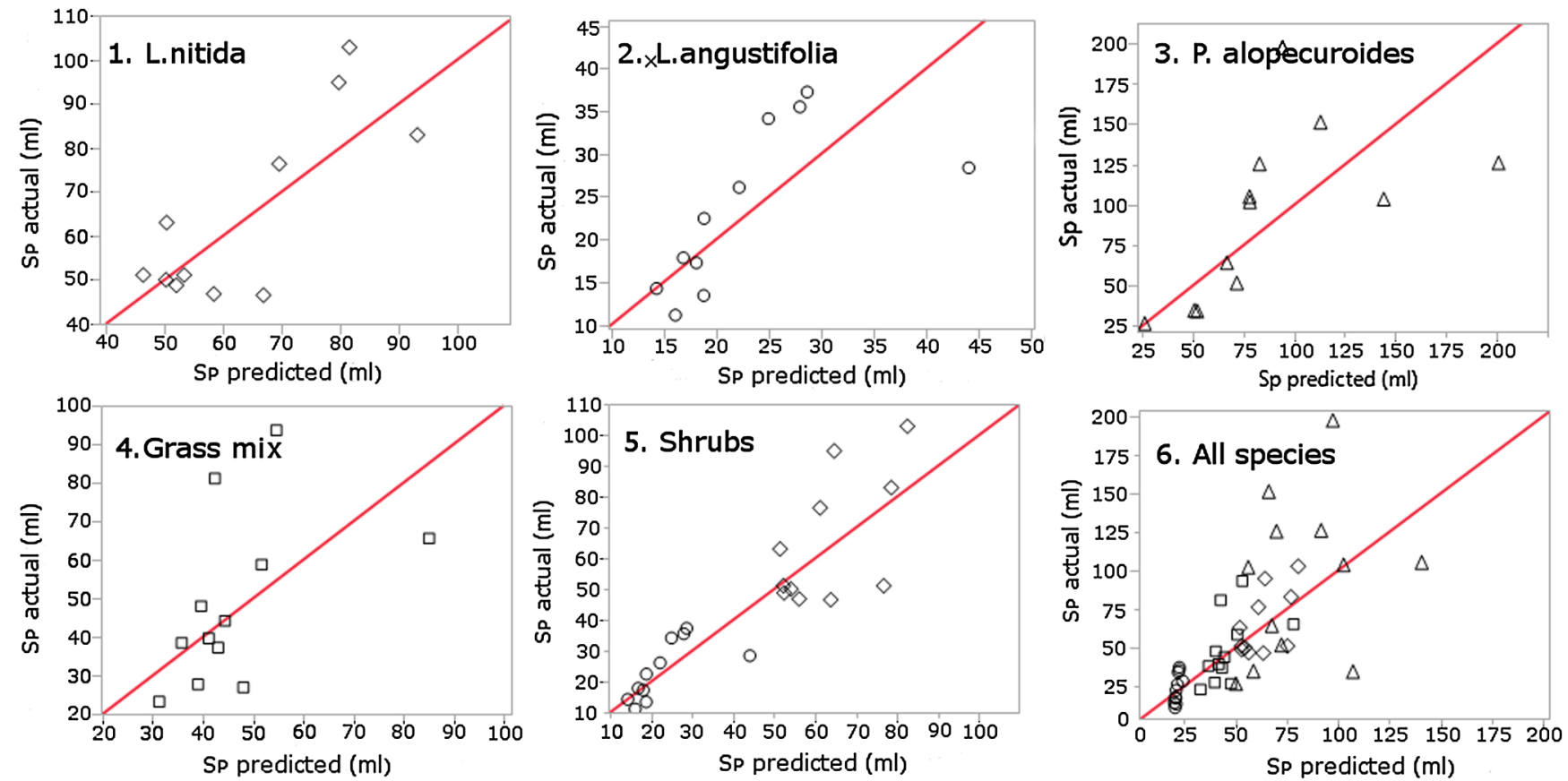

Fig. 7. Actual versus predicted plots of $S_{P}(\mathrm{ml})$. The numbers on the upper left corner of each plot refer to the model number in Table 5 . 
Table 6

Mixed model conversions of models 5 and 6 with the species variable 'i' as random effect.

\begin{tabular}{|c|c|c|c|c|c|c|c|c|}
\hline Number & Model & Model type & $\mathrm{n}$ & Variables & $\mathrm{R}^{2}$ & $\mathrm{R}^{2} \mathrm{adj}$ & RMSE & Species effect \\
\hline 5 & Shrub model & Mixed & 22 & $\mathrm{~B}_{\mathrm{P}}$ (n.s) & 0.77 & 0.76 & 0.32 & $15.8 \%$ \\
\hline 6 & All species & Mixed & 46 & $\mathrm{~B}_{\mathrm{P}}{ }^{* * *}$ & 0.62 & 0.61 & 0.43 & $41.7 \%$ \\
\hline
\end{tabular}

Variables: $\mathrm{B}_{\mathrm{P}}=$ biomass $(\mathrm{g})$.

all models. Branch angle $\left(\mathrm{a}_{\mathrm{B}}\right)$ has an important influence in the $L$. nitida model but not in the $L$. angustifolia model, where $\mathrm{B}_{\mathrm{P}}$ is the only significant predictor variable. A steeper $\mathrm{a}_{\mathrm{B}}$ in the $L$. nitida model increases interception storage capacity. The $P$. alopecuroides model has, besides $\mathrm{B}_{\mathrm{P}}, \mathrm{h}$ and CPA as determining factors. Aside from the grass mix model that has a low fit with an $R^{2}$ and $R^{2}$ adj of 0.34 and 0.27 respectively, all other models demonstrate moderate to good fits with $\mathrm{R}^{2}$ and $\mathrm{R}^{2}$ adj ranging from 0.59 to 0.85 and $0.42-0.82$. The low predictive power of the grass mix model indicates that probably not enough variation was introduced to make a good model. PRESS values are low for the $L$. nitida, L. angustifolia, grass mix- and shrubs models compared to the PRESS values of the $P$. alopecuroides and all species model, indicating good model stability of the former models in comparison to the latter.

When converting the multiple species models (models 5 and 6) to mixed models (Table 6), the species effect accounts for $15.8 \%$ and
$41.7 \%$ of the shrub model and all species model variance respectively. This indicates that in the shrub model, $15.8 \%$ of the measured variance cannot be explained by the residuals of the fixed variables, in this case $\mathrm{B}_{\mathrm{P}}$, but is due to the species variable. The biomass variable in the shrubs model however, becomes insignificant when converting to a mixed model, limiting the model's validity. When converting the all species model to a mixed model, $\mathrm{B}_{\mathrm{P}}$ remains a significant predictor variable.

\subsubsection{Biomass models $B_{P}(g)$}

Table 7 and Fig. 8 show the models made with the $B_{P}(g)$ as dependent variable. The prediction equations can be consulted in the attachments.

Models 1-3 show moderate to good fits with an $R^{2}$ and $R^{2}$ adj ranging from 0.59 to 0.82 and $0.55-0.75$ respectively. No suitable model could be found for the grass mix. In the $L$. nitida model, both $\mathrm{d}$ and $\mathrm{h}$ are

Table 7

Multiple linear regression models for each species separately (model 1-4), both shrubs - L. nitida and L. angustifolia (model 5) and all species together (model 6) with $\mathrm{B}_{\mathrm{P}}(\mathrm{g})$ as dependent variable.

\begin{tabular}{|c|c|c|c|c|c|c|c|c|}
\hline Number & Model & $\mathrm{n}$ & Variables & $\mathrm{R}^{2}$ & $\mathrm{R}^{2} \mathrm{adj}$ & RMSE & ANOVA & PRESS \\
\hline 1 & L. nitida & 12 & $\mathrm{~d}(\mathrm{n} . \mathrm{s}), \mathrm{h}(\mathrm{n} . \mathrm{s}), \mathrm{d}+\mathrm{h}^{* *}$ & 0.82 & 0.75 & 0.12 & $<0,01$ & 0.22 \\
\hline 2 & L. angustifolia & 12 & $a_{L} *, C P A^{* *}$ & 0.74 & 0.69 & 0.16 & $<0,01$ & 0.41 \\
\hline 3 & P. alopecuroides & 12 & $f^{* * *}$ & 0.59 & 0.55 & 0.12 & $<0,01$ & 0.20 \\
\hline 4 & Grass mix & 11 & - & - & - & - & - & - \\
\hline 5 & Shrub model & 24 & $\mathrm{i}^{* * * *}$ & 0.86 & 0.85 & 0.26 & $<0,001$ & 1.81 \\
\hline 6 & All species & 48 & $\mathrm{i}^{* * * *}$ & 0.94 & 0.93 & 0.23 & $<0,001$ & 2,65 \\
\hline
\end{tabular}

$\mathrm{d}=$ diameter $(\mathrm{cm}), \mathrm{h}=$ height $\left(\mathrm{cm}, \mathrm{a}_{\mathrm{L}}=\right.$ average leaf angle $\left(^{\circ}\right), \mathrm{f}=$ no. of inflorescences, $\mathrm{CPA}=$ Canopy projection area $\left(\mathrm{m}^{2}\right), \mathrm{i}=$ species variable n.s. $=$ not significant, $*=p<0.10, * *=p<0.05, * * *=p<0.01,+=$ interaction between variables.

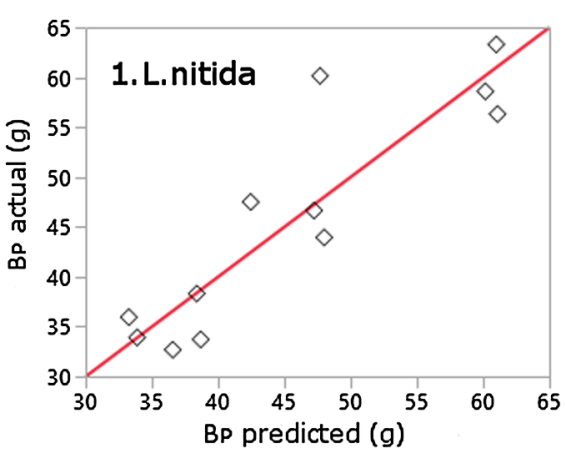

4. Grass mix

No model found
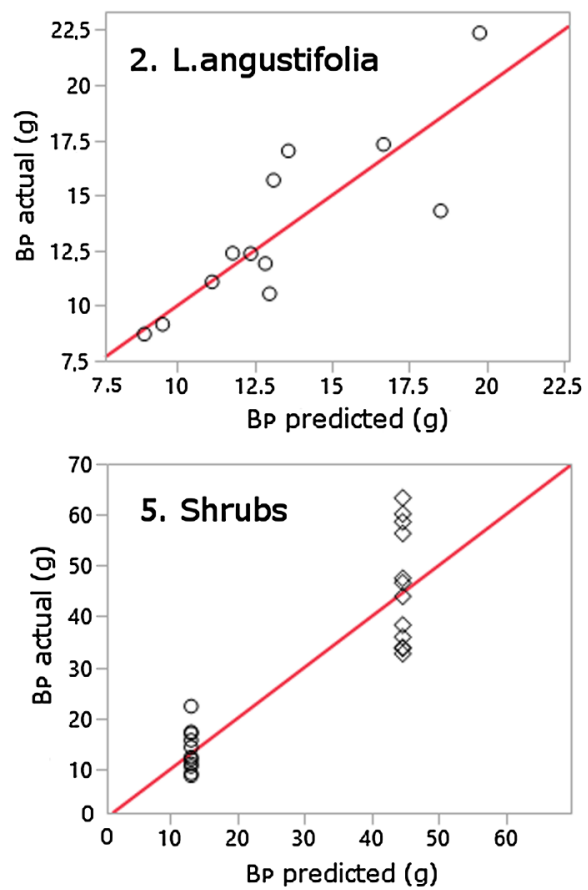
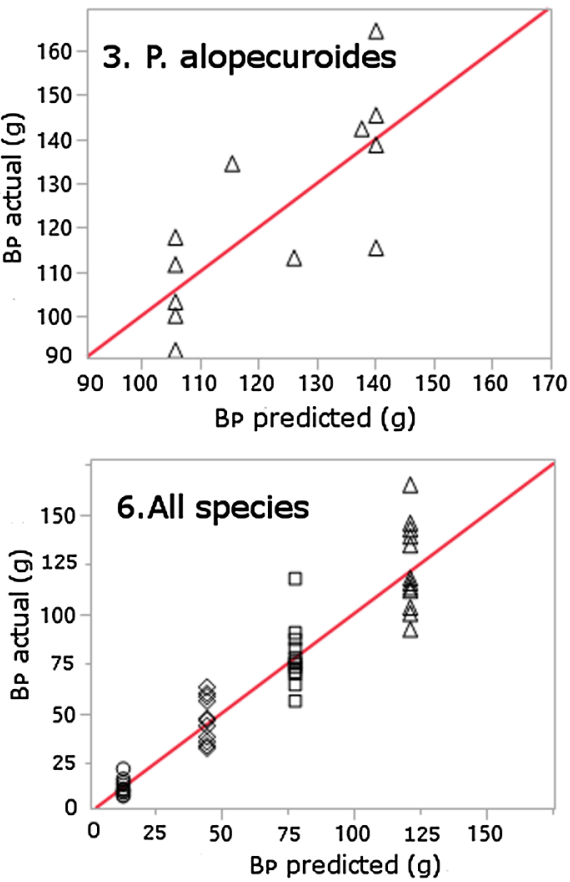

Fig. 8. Actual versus predicted plots of $B_{P}(g)$. The numbers on the upper left corner of each plot refer to the model number in Table 7 . 
not significant, but they are retained because of their interaction effect (heredity principle). The $L$. angustifolia model has $\mathrm{a}_{\mathrm{L}}$ and CPA as predictor variables while the $P$. alopecuroides model displays a reasonable fit with only $f$ as predictor variable.

The shrub- and all species model show very good model fits with an R2 and R2adj of $0.86-0.94$ and $0.85-0.93$ respectively. The only variable in the models is the species variable ' $i$ '. This means that only one biomass value is given for each species as output and that converting models 5 and 6 to a mixed model is impossible as there would be no fixed variables in the model.

\subsubsection{Reverse estimation $S_{P}$}

In this section $S_{p}$ will be reverse estimated by using the output of the $B_{P}$ models (Table 7 ) as input for the $S_{P}$ models (Table 5). Doing this gives an indication of the applicability of the whole modelling
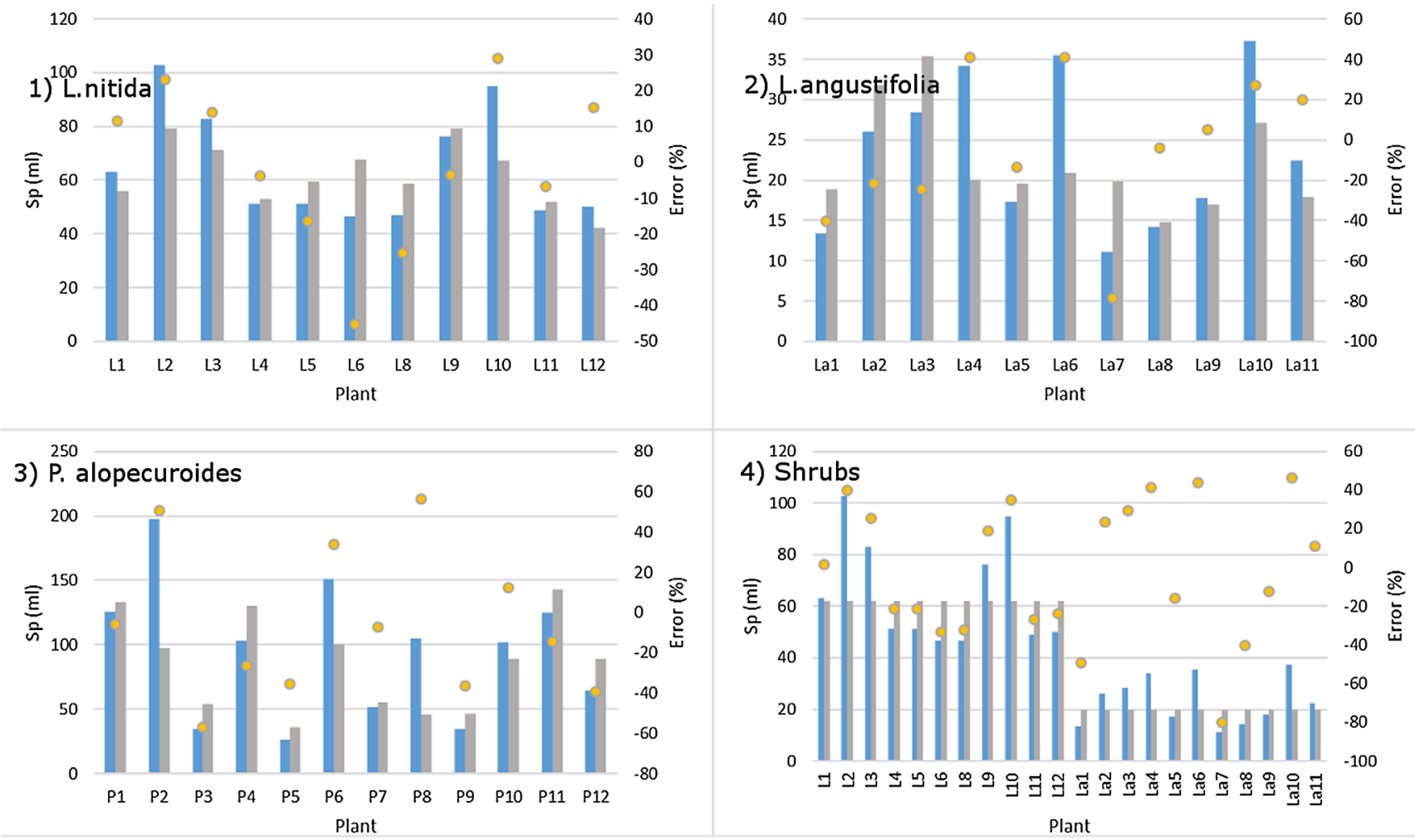

250

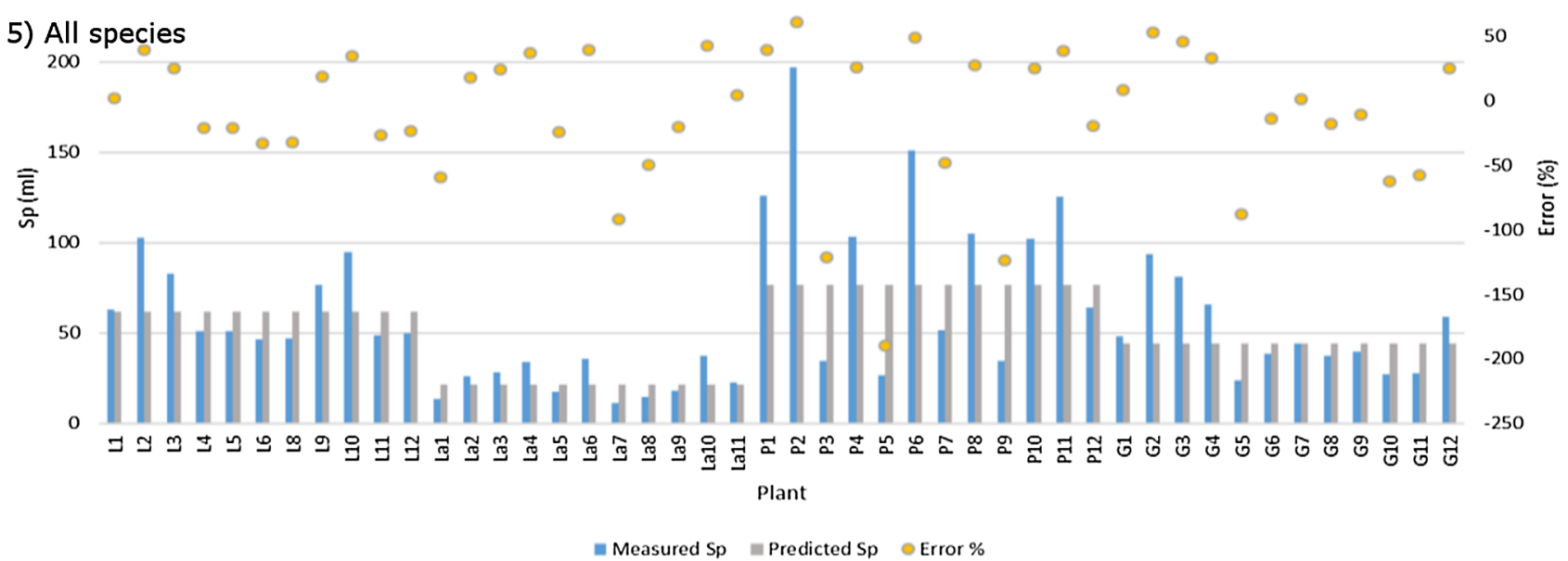

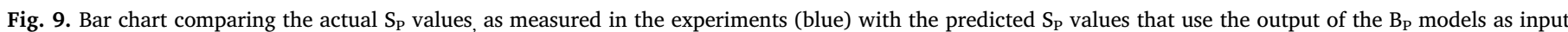

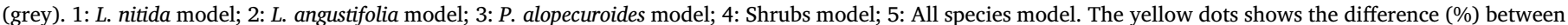
the actual- and predicted $S_{P}$ values. (For interpretation of the references to color in this figure legend, the reader is referred to the web version of this article.) 
Table 8

Error values of reverse Sp estimation model output, all values are in \%.

\begin{tabular}{|c|c|c|c|c|c|c|c|}
\hline Number & Model & $\mathrm{n}$ & Average error & Average abs. Error & Median abs. error & Min error & Max error \\
\hline 1 & L. nitida & 11 & -0.7 & 17.7 & 15.4 & 3.6 & 45.2 \\
\hline 2 & L. angustifolia & 11 & -4.4 & 28.9 & 24.7 & 3.8 & 78.4 \\
\hline 3 & P. alopecuroides & 12 & -5.7 & 31.3 & 34.8 & 5.6 & 56.9 \\
\hline 4 & Shrub model & 22 & 2.6 & 30.5 & 28.2 & 1.8 & 79.9 \\
\hline 5 & All species & 46 & -9.4 & 40.8 & 32.7 & 0.9 & 189.7 \\
\hline
\end{tabular}

4 and 5 is constant for each species (Fig. 9), which is a direct result of the discrete output of $B_{p}$ models 5 and 6 (Table 7).

\section{Discussion}

\subsection{Ex-situ experiments}

Comparing the interception storage capacities found with our experiments to values of previous studies done on similar plants, the results found in this research are of similar magnitude. Garcia-Estringana et al. (2010) found an $S_{B}$ for L. latifolia, a plant of the same genus as $L$. angustifolia, of $2.26 \mathrm{ml} / \mathrm{g}$ while this study found a value of $1.64 \pm 0.41 \mathrm{ml} / \mathrm{g}$ for L. angustifolia. Upscaling their results, they found an $\mathrm{S}_{\mathrm{CPA}}$ of $3.24 \pm 1.17 \mathrm{~mm}$ while this study found $4.22 \pm 1.83 \mathrm{~mm}$. Domingo et al. (1998) empirically derived interception storage capacities for Stipa tenacissima L. tussock, a perennial grass with similar morphology to $P$. alopecuroides and found an $\mathrm{S}_{\mathrm{CPA}}$ of $2.44 \pm 0.27 \mathrm{~mm}$. The results in this study are slightly higher with $2.97 \pm 1.89 \mathrm{~mm}$.

Shrubs had considerably higher $S_{B}$ than grasses (Table 4). This difference might be explained by the woody branch architecture of shrubs, as described by Pérez-Harguindeguy et al. (2013). Shrub canopies, consisting of diverging primary and secondary branches, are well suited to hold water droplets because the woody tissue acts as an additional water storage reservoir. Xiao and McPherson (2016) found that water stored on stem surfaces of tree branches could amount up to $0.16 \mathrm{~mm}$ per unit stem surface area. Herbaceous plants such as grasses on the other hand consist entirely of green tissue, making them less suitable for temporal water storage.

\subsection{Modelling}

The storage capacity models (Table 5 ) show that $\mathrm{B}_{\mathrm{P}}$ is the most important predictor variable. These findings are in accordance with Wang et al. (2012), who acknowledges the importance of $B_{p}$ : they found $\mathrm{B}_{\mathrm{P}}$ and leaf area to be the best predictors for canopy storage capacity for three xerophytic shrub types. Keim et al. (2006) on the other hand, found that $\mathrm{B}_{\mathrm{P}}$ did not correlate well to storage capacity.

Variables such $\mathrm{as}_{\mathrm{B}}$ for the L. nitida model and CPA and $\mathrm{h}$ for the $P$. alopecuroides model are additional factors improving model fit. These findings are in accordance to Garcia-Estringana et al. (2010), who found $B_{P}$ and dendrometric characteristics to be significantly correlated to $S_{P}$. The positive coefficient of $a_{B}$ in the $L$. nitida model (see appendix) indicates that a higher $\mathrm{a}_{\mathrm{B}}$ is beneficial for water storage. In literature, an $a_{B}$ above $45^{\circ}$ is usually associated with greater stemflow yields (Levia and Frost, 2003; Martinez-Meza and Whitford, 1996). With an $\mathrm{a}_{\mathrm{B}}$ of $46.3+8.3^{\circ}$, the branches of $L$. nitida are around this threshold value of favoring water storage or stemflow, but the limited variation in $\mathrm{a}_{\mathrm{B}}$ does not allow to determine this exact value.

For the storage capacity models encompassing more than one species, the species effect significantly improved both the shrub- and all species model. This means that there are other specific characteristics, not covered in this research, that influence $S_{P}$. What these characteristics are remains an open topic to debate. Characteristics such as stem pubescence or epidermal rugosity could influence $S_{p}$ (Garcia-Estringana et al., 2010) and the effect of leaf hydrophobicity and water droplet retention were also not accounted for in this study (Holder, 2013). Pérez-Harguindeguy et al. (2013) states that the hydrophobicity or wettability of a leaf surface is mainly determined by the leaves' cuticular wax and trichomes. Taking these characteristics into account is advised for possible follow up studies. When converting these models to a mixed model (Table 6), the magnitude of the species effect is evaluated. The species effect is small (15.8\%) for the shrub model, but after conversion $\mathrm{B}_{\mathrm{p}}$ becomes insignificant as a predictor variable, severely limiting the applicability of this model. The all species model has a larger (47.7\%) species effect, meaning a larger uncertainty when using other species than the ones included in the model. The variable $\mathrm{B}_{\mathrm{P}}$ however remains significant, meaning the model can be used to predict $\mathrm{S}_{\mathrm{P}}$ of other plant species. This larger uncertainty was expected because of the higher number of species in the model with a widely different morphology such as the differences between grasses and shrubs.

The $\mathrm{B}_{\mathrm{P}}$ models (Table 7) show good fits for L. nitida, L. angustifolia and $P$. alopecuroides, using some easy to measure variables. For the grass mix no $B_{P}$ model could be found which reflects the lesser results of the $\mathrm{S}_{\mathrm{P}}$ model. The most probable cause for this is that not enough variation was introduced by adjusting the vegetation characteristics of the grass (Table 2). Follow up studies should make sure to introduce more variation. The shrub- and all species models show very high fits but this is as a result of the species variable, which is the only significant predictor in these models, all other variables are negligible. This results in a discrete model output of only one $B_{P}$ value for each species, limiting these models' applicability.

\subsection{Applicability}

The $B_{P}$ models 1-3 provided in Table 7 can be used to estimate $B_{P}$ of an individual plant using some easy to measure vegetation characteristics. These model outputs can then be used as input for the models in Table 5, giving an estimation of $S_{P}$. The reverse estimation of $S_{P}$, using the output values of the $B_{P}$ models as input, is a valuable test of the general applicability of the whole modelling procedure. All models perform similar with slightly larger error values for the shrubs- and all species model, which is expected because of the discrete output of the biomass models that is used as input. Especially the $B_{p}$ and $S_{p}$ models 1-3 are applicable for intra-species estimation of biomass and storage capacity, given their good model fits and reasonable average absolute errors in the reverse $S_{p}$ estimation procedure. The shrubs- and all species models are useful when the modeler's interest lies in distinguishing $B_{P}$ and $S_{P}$ between species. Because of their species-specific discrete output, these models are not suited for intra-species $B_{P}$ and $S_{P}$ estimation. Although reasonable results are achieved in the reverse $S_{P}$ estimation, we advise to use the output values of the biomass models with caution and to compare them with alternative biomass estimation methods before using them as input in the $S_{P}$ models.

These results can then be extrapolated to $S_{\mathrm{CPA}}$ using the CPA (Section 2.5). The results of the grass mix $S_{P}$ model are less suited for application. The $S_{P}$ values found in the rain experiments nevertheless can be used as an average for common lawn because the average mowing height of urban lawn (Day, 2017) is within the range used in our experiments (Table 3).

The mixed models (Table 6) give a proof of concept on how to 
incorporate more species in the regression models. To make these models more applicable, experiments should be done with more plant species with a wider range of morphological characteristics to decrease the species effect.

Comparing the interception storage potential of urban trees and smaller urban vegetation types, certain advantages are seen when using the latter. Indeed, this study found that, on average, the storage capacity of small green is comparable and in some cases higher than that of urban trees. In this study, $\mathrm{S}_{\mathrm{CPA}}$ values of $4.22 \pm 1.83 \mathrm{~mm}$ (L. angustifolia), $2.97 \pm 1.89 \mathrm{~mm}$ (P. alopecuroides), $1.21 \pm 0.39 \mathrm{~mm}$ (L. nitida) and $0.67 \pm 0.26 \mathrm{~mm}$ (grass mix) were found. In comparison Aston (1979) found $\mathrm{S}_{\mathrm{CPA}}$ between 0.2 and $1.04 \mathrm{~mm}$ in his rainfall simulation experiments on eight small trees. More recently Xiao et al. (2000b) found $\mathrm{S}_{\mathrm{CPA}}$ values of 1 and $2 \mathrm{~mm}$ for a Pyrus calleryana 'Bradford' and Quercus suber respectively, while Véliz-chávez et al. (2014) found an average $\mathrm{S}_{\mathrm{CPA}}$ of $1.5 \mathrm{~mm}$ for a Ficus benjamina tree. Interestingly, Iida et al. (2017) recently found $S_{\mathrm{CPA}}$ values of 5.9-7.2 mm for Japanese cedar trees. They explained these high water storage values are a result of high bark and branch storage, which constitutes $70-90 \%$ of total water storage. It seems that small green elements are a comparable or sometimes even more efficient rainfall storage container than most trees. This study recommends performing more research in both controlled- and in situ conditions to improve the models presented in this study and enhance our understanding of the interception storage capacity potential of small green species.

\section{Conclusions}

This study looked at the interception storage capacity potential of four urban plants species with different morphological characteristics. Rainfall simulations in controlled conditions allowed to determine $S_{P}$ of the common green species L. nitida, L. angustifolia, P. alopecuroides and a grass mix. Using multiple linear regression models, $B_{P}$ was found to be the most important predictor variable for all species. Therefore $B_{P}$ prediction models were constructed, with vegetation characteristics that are easily measured in the field, to serve as input for the $S_{P}$ models. The results of these $S_{P}$ models using $B_{P}$ as input were reasonable with relatively low absolute errors between predicted- and actual $S_{\mathrm{P}}$, demonstrating their practical applicability. A mixed modelling approach was proposed to obtain $S_{P}$ for species not included in this research. The results obtained with this approach give support for further studies, incorporating more species, with more individuals, to improve model prediction accuracy and determine the overall effect of biomass on interception storage capacity.

\section{Declarations of interest}

None.

\section{Acknowledgements}

Funding: This work was supported by the Fonds Wetenschappelijk Onderzoek Vlaanderen (FWO) [FWO-SB, Grant 151124]. The funding institution played no role in the study design, collection, analysis or interpretation of data; in the writing of the report; or in the decision to submit the article for publication

\section{Appendix}

Model prediction equations:

Each variable $\mathrm{X}$ is recoded to a variable $\mathrm{X}$ (c) to reduce multicollinearity and scale effects. The coded variable is dimensionless and has values between $[-1,1]$.

The coding is done by the formula: $X(c)=\frac{X-M}{D}$ where:

$\mathrm{M}$ is the arithmetic mean of variable $\mathrm{X}$ which is found by the formula: $M=\frac{\max (X)+\min (X)}{2}$

$\mathrm{D}$ is the range of variable $\mathrm{X}$ divided by two: $\mathrm{D}=\frac{\max (X)-\min (X)}{2}$

Coded variable:

$$
\begin{aligned}
& B p(c)=\left(\frac{B p(g)-502.29}{493.58}\right) \\
& a^{B}(c)=\left(\frac{a B\left(\hat{A}^{\circ}\right)-56.14}{24.32}\right) \\
& C P A(c)=\left(\frac{C P A\left(m^{2}\right)-0.12}{0.12}\right) \\
& h(c)=\left(\frac{h(c m)-33.84}{32.66}\right) \\
& a^{L}(c)=\left(\frac{a^{L}\left(\hat{\mathrm{A}}^{\circ}\right)-31.22}{38.48}\right) \\
& f(c)=\left(\frac{f(\#)-15}{8}\right)
\end{aligned}
$$

(c) stands for 'coded'

\section{A) Fixed storage capacity models (ml) - Table 5 .}

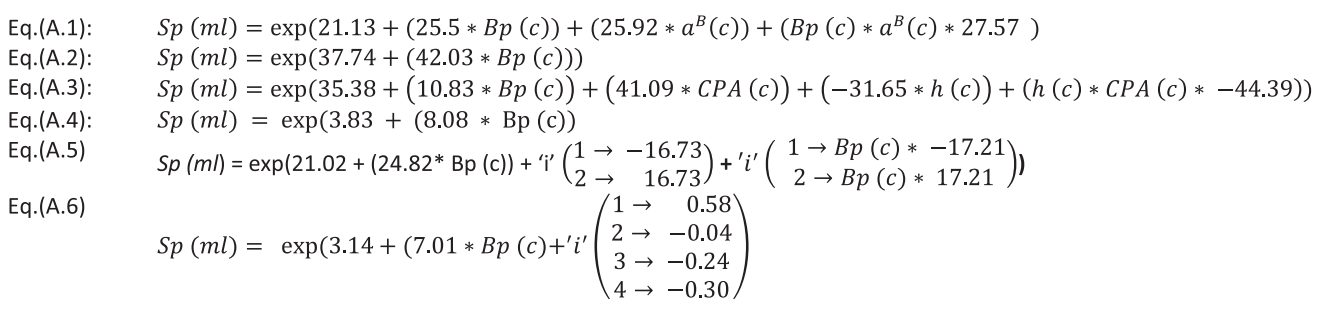

$1 \rightarrow$ L. nitida; $2 . \rightarrow$ L. angustifolia; $3 \rightarrow P$. alopecuroides; $4 \rightarrow$ Grass mix 
B) Mixed storage capacity models (ml) - Table 6 .

Eq.(B.1): $\quad S p(m l)=\exp (10.32+(14.23 * \mathrm{Bp}(\mathrm{c})))$

Eq.(B.2): $\quad S p(m l)=\exp (2.19+(5.94 * B p(c)))$

C) Fixed biomass models (g) - Table 7 .

$\begin{array}{ll}\text { Eq.(C.1): } & B p(g)=\exp (3.77+(0.11 * h(c))+(0.003 * d(c))+(h(c) *(d(c)-30.3) *-0.04)) \\ \text { Eq.(C.2): } & B p(g)=\exp \left(9.16+(6.87 * C P A(c))+\left(0.33 * a^{L}(c)\right)\right) \\ \text { Eq.(C.3): } & B p(g)=\exp (4.80+(0.14 * f(c)))\end{array}$

Eq.(C.4): $\quad$ No model found for the grass mix

Eq.(C.5): $\quad B p(g)=\exp \left(3.19+{ }^{\prime} i^{\prime}\left(\begin{array}{cc}1 \rightarrow & +0.61 \\ 2 \rightarrow & -0.61\end{array}\right)\right)$

Eq.(C.6):

$$
B p(g)=\exp \left(3.88++^{\prime} i^{\prime}\left(\begin{array}{l}
1 \rightarrow-0.08 \\
2 \rightarrow-1.31 \\
3 \rightarrow+0.47 \\
4 \rightarrow+0.92
\end{array}\right)\right)
$$

$1 \rightarrow$ L. nitida; $2 . \rightarrow$ L. angustifolia; $3 \rightarrow$ P. alopecuroides; $4 \rightarrow$ Grass mix

\section{References}

Aston, A.R., 1979. Rainfall interceptcion by eight small trees. J. Hydrol. 42, 383-396. https://doi.org/10.1016/0022-1694(79)90057-X.

Cameron, R.W.F., Blanuša, T., 2016. Green infrastructure and ecosystem services - is the devil in the detail? Ann. Bot. 118, 377-391. https://doi.org/10.1093/aob/mcw129.

Ciria, 2013. Demonstrating the multiple benefits of SuDS - a business case (Phase 2)

Concilio, A.L., Prevéy, J.S., Omasta, P., O'Connor, J., Nippert, J.B., Seastedt, T.R., 2015. Response of a mixed grass prairie to an extreme precipitation event. Ecosphere 6, 1-12. https://doi.org/10.1890/ES15-00073.1.

Coutts, A.M., Tapper, N.J., Beringer, J., Loughnan, M., Demuzere, M., 2012. Watering our cities : The capacity for Water Sensitive Urban Design to support urban cooling and improve human thermal comfort in the Australian context. Prog. Phys. Geogr. 1-27. https://doi.org/10.1177/0309133312461032.

Day, J., 2017. What Is the Proper Mowing Height for Grass in Your Yard? [WWW Document]. URL https://www.todayshomeowner.com/what-is-the-proper-mowingheight-for-grass-in-your-yard/.

Demuzere, M., Coutts, A.M., Göhler, M., Broadbent, A.M., Wouters, H., Van Lipzig, N.P., Gebert, L., 2014. Urban Climate The implementation of biofiltration systems, rainwater tanks and urban irrigation in a single-layer urban canopy model. Urban Clim. 10, 148-170. https://doi.org/10.1016/j.uclim.2014.10.012.

Dewaelheyns, V., Rogge, E., Gulinck, H., 2014. Putting domestic gardens on the agenda using empirical spatial data: the case of Flanders. . Appl. Geogr. 50, 132-143. https:// doi.org/10.1016/j.apgeog.2014.02.011.

Dietz, M.E., 2007. Low impact development practices: a review of current research and recommendations for future directions. Water Air Soil Pollut. 186, 351-363. https:// doi.org/10.1007/s11270-007-9484-z.

Domingo, F., Sánchez, G., Moro, M.J., Brenner, A.J., Puigdefábregas, J., 1998. Measurement and modelling of rainfall interception by three semi-arid canopies. Agric. For. Meteorol. 91, 275-292. https://doi.org/10.1016/S0168-1923(98) 00068-9.

Dunkerley, D., 2000. Measuring interception loss and canopy storage in dryland vegetation: a brief review and evaluation of available research strategies. Hydrol. Process. 14, 669-678. https://doi.org/10.1002/(SICI)1099-1085(200003)14:4<669::AIDHYP965 > 3.0.CO;2-I.

FAWB, n.d. Adoption guidelines for stormwater biofiltration systems, June 2009. ed. Facility for Advancing Water Biofiltration, Monash University.

Garcia-Estringana, P., Alonso-Blázquez, N., Alegre, J., 2010. Water storage capacity, stemflow and water funneling in Mediterranean shrubs. J. Hydrol. 389, 363-372. https://doi.org/10.1016/j.jhydrol.2010.06.017.

Gash, J.H.C., 1979. An analytical model of rainfall interception by forests. Q. J. R. Meteorol. Soc. 105, 43-55. https://doi.org/10.1002/qj.49710544304.

Goos, P., Jones, B., 2011. Optimal design of experiments a case study approach.

Haase, D., 2009. Effects of urbanisation on the water balance - a long-term trajectory. Environ. Impact Assess. Rev. 29, 211-219. https://doi.org/10.1016/j.eiar.2009.01. 002

Holder, C.D., 2013. Effects of leaf hydrophobicity and water droplet retention on canopy storage capacity. Ecohydrology 6, 483-490. https://doi.org/10.1002/eco.1278.

Holder, C.D., Gibbes, C., 2017. Influence of leaf and canopy characteristics on rainfall interception and urban hydrology. Hydrol. Sci. J. 62, 182-190. https://doi.org/10. 1080/02626667.2016.1217414.

Iida, S., Levia, D.F., Shimizu, A., Shimizu, T., Tamai, K., Nobuhiro, T., Kabeya, N., Noguchi, S., Sawano, S., Araki, M., 2017. Intrastorm scale rainfall interception dynamics in a mature coniferous forest stand. J. Hydrol. 548, 770-783. https://doi.org/ 10.1016/j.jhydrol.2017.03.009.

Jacobson, C.R., 2011. Identification and quantification of the hydrological impacts of imperviousness in urban catchments: a review. J. Environ. Manage. 92, 1438-1448. https://doi.org/10.1016/j.jenvman.2011.01.018.

Keim, R.F., Skaugset, A.E., Weiler, M., 2006. Storage of water on vegetation under simulated rainfall of varying intensity. Adv. Water Resour. 29, 974-986. https://doi. org/10.1016/j.advwatres.2005.07.017.

Kincaid, D., Solomon, K., Oliphant, J.C., 1996. Drop size distributions for irrigation sprinklers. Trans. ASAE 39, 839-845. https://doi.org/10.13031/2013.32550.

Levia, D.F., Frost, E.E., 2003. A review and evaluation of stemflow literature in the hydrologic and biogeochemical cycles of forested and agricultural ecosystems. J. Hydrol. 274, 1-29. https://doi.org/10.1016/S0022-1694(02)00399-2.

Livesley, S.J., McPherson, G.M., Calfapietra, C., 2016. The urban forest and ecosystem services: impacts on urban water, heat, and pollution cycles at the tree, street, and city scale. J. Environ. Qual. 45, 119-124. https://doi.org/10.2134/jeq2015.11.0567.

Martinez-Meza, E., Whitford, W.G., 1996. Stemflow, throughfall and channelization of stemflow by roots in three Chihuahuan desert shrubs. J. Arid Environ. 32, 271-287 https://doi.org/0140-1963/96/030271.

Martin-Ortega, J., Ferrier, R.C., Gordon, I.J., Khan, S., 2015. In: Water Ecosystem Services: A Global Perspective, International Hydrology Series. . Cambridge University Press. https://doi.org/10.1017/CBO9781107415324.004.

Mcgill, R., Tukey, J.W., Larsen, W.A., 1978. Variations of box plots. Am. Stat. 32, 12-16.

Muzylo, A., Llorens, P., Valente, F., Keizer, J.J., Domingo, F., Gash, J.H.C., 2009. A review of rainfall interception modelling. J. Hydrol. 370, 191-206. https://doi.org/10. 1016/j.jhydrol.2009.02.058.

Neter, John, Kutner, Michael H., Nachtsheim, Christopher J., Li, William, 2004. Applied Linear Statistical Models, fifth ed. McGraw- Hill/Irwin.

Paul, M.J., Meyer, J.L., 2001. Streams in the Urban Landscape. Annu. Rev. Ecol. Syst. 32 333-365. https://doi.org/10.1146/annurev.ecolsys.32.081501.114040.

Pérez-Harguindeguy, N., Díaz, S., Lavorel, S., Poorter, H., Jaureguiberry, P., Bret-Harte, M.S., Cornwell, W.K., Craine, J.M., Gurvich, D.E., Urcelay, C., Veneklaas, E.J., Reich, P.B., Poorter, L., Wright, I.J., Ray, P., Enrico, L., Pausas, J.G., De Vos, A.C., Buchmann, N., Funes, G., Quétier, F., Hodgson, J.G., Thompson, K., Morgan, H.D., Ter Steege, H., Heijden, M.G., Van Der, A., Sack, L., Blonder, B., Poschlod, P., Vaieretti, M.V., Conti, G., Staver, A.C., Aquino, S., Cornelissen, J.H.C., 2013. New Handbook for standardized measurment of plant functional traits worldwide. Aust. J. Bot. 61, 167-234. https://doi.org/10.1071/BT12225.

Revi, A., Aragón-Durand, F., Corfee-Morlot, J., Kiunsi, R.B., Pelling, M., Roberts, D.C., Soleck, W., 2014. Urban areas. Clim. Chang. In: 2014 Impacts, Adapt. Vulnerability. Part A Glob. Sect. Asp. Contrib. Work. Gr. II to Fifth Assess. Rep. Intergov. Panel Clim. Chang. pp. 535-612. https://doi.org/10.1017/CBO9781107415379.013.

Rutter, A.J., Kershaw, K.A., Robins, P.C., Morton, A.J., 1971. A predictive model of rainfall interception in forests, 1 . Derivation of the model from observations in a plantation of Corsican pine. . Agric. Meteorol. 9, 367-384. https://doi.org/10.1016/ 0002-1571(71)90034-3. 
Véliz-chávez, C., Mastachi-loza, C.A., González-sosa, E., Becerril-piña, R., Ramos-salinas, N.M., 2014. Canopy storage implications on interception loss modeling. Am. J. Plant Sci. 5, 3032-3048. https://doi.org/10.4236/ajps.2014.520320 Canopy.

Verbeeck, K., Van Rompuy, R., Hermy, M., Van Orshoven, J., 2013. Infiltrating into the paved garden - a functional evaluation of parcel imperviousness in terms of water retention efficiency. J. Environ. Plan. Manage. 57, 1552-1571. https://doi.org/10. 1080/09640568.2013.819317.

Wang, X.P., Zhang, Y.F., Hu, R., Pan, Y.X., Berndtsson, R., 2012. Canopy storage capacity of xerophytic shrubs in Northwestern China. J. Hydrol. 454-455, 152-159. https:// doi.org/10.1016/j.jhydrol.2012.06.003.

Wohlfahrt, G., Bianchi, K., Cernusca, A., 2006. Leaf and stem maximum water storage capacity of herbaceous plants in a mountain meadow. J. Hydrol. 319, 383-390. https://doi.org/10.1016/j.jhydrol.2005.06.036.

Wong T.H.F., Allen R., Brown R.R., Deletić A., Gangadharan L., Gernjak W., Jakob C., Johnstone P., Reeder M., Tapper N., Vietz, G. and W.C.J., 2013. blueprint2013 Stormwater management in a water sensitive city, Cooperative Research Centre for Water Sensitive Cities. Melbourne, Australia.

Xiao, Q., Mcpherson, E.G., Forest, U., Ustin, S.L., Grismer, M.E., Abstract, A., 2000a. A new approach to modeling tree rainfall interception. J. Geophys. Res. 105, 29173-29188. https://doi.org/10.1029/2000JD900343.

Xiao, Q., McPherson, E.G., 2016. Surface water storage capacity of twenty tree species in Davis, California. J. Environ. Qual. 45, 188-198. https://doi.org/10.2134/jeq2015. 02.0092.

Xiao, Q., Mcpherson, E.G., Ustin, S.L., Grismer, M.E., Simpson, J.R., 2000b. Winter rainfall interception by two mature open-grown trees in Davis. California. Hydrol. Process. 14, 763-784. https://doi.org/10.1002/(SICI)1099-1085(200003)14:4.

Xiao, Q., McPherson, E.G., 2011. Rainfall interception of three trees in Oakland, California. Urban Ecosyst. 14, 755-769. https://doi.org/10.1007/s11252-011 0192-5.

Zhang, Y.F., Wang, X.P., Hu, R., Pan, Y.X., Paradeloc, M., 2015. Rainfall partitioning into throughfall, stemflow and interception loss by two xerophytic shrubs within a rainfed re-vegetated desert ecosystem, northwestern China. J. Hydrol. 527, 1084-1095. https://doi.org/10.1016/j.jhydrol.2015.05.060.

Zou, C.B., Caterina, G.L., Will, R.E., Stebler, E., Turton, D., 2015. Canopy interception for a tallgrass prairie under juniper encroachment. PLoS One 10,1-19. https://doi.org/ 10.1371/journal.pone.0141422. 